\title{
The Impact of the Entry of Biosimilars: Evidence from Europe
}

\section{Citation}

Scott Morton, Fiona M., Ariel Dora Stern, and Scott Stern. "The Impact of the Entry of Biosimilars: Evidence from Europe." Review of Industrial Organization 53, no. 1 (August 2018): 173-210.

\section{Published Version}

https://link.springer.com/article/10.1007\%2Fs11151-018-9630-3

\section{Permanent link}

http://nrs.harvard.edu/urn-3:HUL.InstRepos:41292244

\section{Terms of Use}

This article was downloaded from Harvard University's DASH repository, and is made available under the terms and conditions applicable to Open Access Policy Articles, as set forth at http:// nrs.harvard.edu/urn-3:HUL.InstRepos:dash.current.terms-of-use\#OAP

\section{Share Your Story}

The Harvard community has made this article openly available.

Please share how this access benefits you. Submit a story.

Accessibility 


\section{The Impact of the Entry of Biosimilars: Evidence from Europe}

Fiona M. Scott Morton

Ariel Dora Stern

Scott Stern

Working Paper 16-141 


\title{
The Impact of the Entry of Biosimilars: Evidence from Europe
}

\author{
Fiona M. Scott Morton \\ Ariel Dora Stern \\ Scott Stern
}

Working Paper 16-141 


\title{
THE IMPACT OF THE ENTRY OF BIOSIMILARS: EVIDENCE FROM EUROPE
}

\author{
Fiona M. Scott Morton, Ariel Dora Stern, and Scott Stern* \\ July, 2017
}

Biologic drugs (therapeutic proteins or "large-molecule drugs") represent a substantial and growing share of the U.S. drug market, accounting for less than $1 \%$ of prescriptions filled but over a quarter of dollars spent. Whereas traditional (chemically-synthesized, "small-molecule") drugs face price competition from generic drugs after patent expiration, biosimilars - biologic drugs that have been shown to be therapeutically equivalent to an already approved original biologic drug - do not yet play the same role, having only been approved in the United States since 2015. Europe, however, has had biosimilar entry since 2006; we consider how competition from biosimilars may impact the U.S. biosimilar market by examining data from the first eight years of biosimilar competition in 23 European countries. We develop a detailed survey that allows us to precisely characterize European biologic drug procurement institutions over time. Using data from three classes of biosimilar drugs, we analyze how market features and public policies predict entry, market prices, and penetration of biosimilars. We find significant heterogeneity across countries and drug classes among all outcomes. While traditional predictors of entry, such as market size are significant, we also observe that effective buyer institutions (in particular, committed tenders) are associated with increased biosimilar penetration. Price patterns are more difficult to glean from the available data. Our estimates can inform ongoing policy discussions on both sides of the Atlantic about the economic implications of biosimilar policies.

\footnotetext{
*We are grateful to Ernie Berndt, Bill Comanor, Innessa Colaiacovo, James Leung, Robert Meyer, Andrew Mulcahy, Stacy Springs, Robert Town, and seminar participants at Boston University, UCLA, the Kellogg Health Care Markets Conference, Harvard Business School, Harvard Medical School, Tulane University, the University of Virginia, IFS, KU Leuven, ASHEcon, the NBER Productivity Lunch, and the Bates White Life Sciences Symposium for helpful suggestions. Several experts in and well acquainted with the health ministries of European countries in our sample provided valuable information on domestic drug procurement policies. Suzette Kox, Julie Maréchal, Pieter Dylst, and Maarten Van Baelen from Medicines for Europe were particularly generous with their time. Prof. Fernando de Mora in the Department of Pharmacology, Therapeutics and Toxicology at the Universitat Autònoma de Barcelona - Spain provided detailed scientific and regulatory detail. Melissa Ouellet, Oliver Falvey, Lila Kelso, Brittany Ngo, and Kathrin Lampert provided excellent research and editorial assistance. Funding from the National Science Foundation award number 1064341 (The Industrial Organization of the Biologics Industry: Theory, Empirics and Policy) and the National Institute on Aging, through grant number T32-AG000186 to the National Bureau of Economic Research, is gratefully acknowledged. We are particularly appreciative of access to IMS data provided by Pfizer Inc. and IMS.
} 


\section{INTRODUCTION}

A central challenge facing health care policymakers is balancing the provision of innovation incentives for private firms with access to medical technologies at a reasonable margin above the cost of production. In the area of pharmaceuticals, one approach to managing this trade-off is a policy regime in which there is entry regulation during the time in which a drug is protected by patent-based intellectual property rights, followed by active encouragement of entry and price competition after the expiration of its key patent(s). In the United States, the 1984 HatchWaxman Act provides innovator pharmaceutical firms with a longer period of guaranteed exclusivity in exchange for the ability for generic drug manufacturers to subsequently enter markets through an abbreviated regulatory process in which generic manufacturers are only required to demonstrate "bioequivalence" between a generic candidate and the reference product (Grabowski and Vernon, 1986; Scott Morton, 1999).

While this regime has involved policy challenges over time as the result of the strategic interaction among pioneer and generic firms (see, for example, Scott Morton, 2000, or Bulow, 2004), there is a relatively consistent body of evidence that the Hatch-Waxman regime was efficacious for the types of chemically-synthesized drugs that had been the mainstay of the pharmaceutical industry through the 1990s, particularly once buyer institutions developed products that facilitated price competition between branded and generic products after patent expiration (Hamburg, 2014; Reiffen and Ward, 2005).

However, whereas most new drugs prior to 1990 were "small-molecule" compounds whose chemical composition could be copied exactly by a generic manufacturer, a new class of drugs began to appear starting in the 1980s: biologics, which are therapeutic proteins derived from biologic sources. Due to their biologic origin and complexity, biologics typically involve a high 
marginal manufacturing cost on a per-patient basis, and cannot simply be copied based on a molecular formula as in the case for traditional, small-molecule generic products. As a result of this technological change, the existing regulatory regime for approving follow-on products after a drug's primary patent expiration was not applicable for these products. A new policy regime was therefore required - one that would encourage entry after patents on original biologics expired, even though follow-on entrants would only be able to demonstrate "biosimilarity" - a very high level of structural homology with no significant changes of safety and efficacy - rather than an exact match between pioneer and generic drug's active molecular ingredient.

In the early 2000s, a sharp divide emerged between the United States and Europe in the development and implementation of a new regulatory pathway for biosimilars. On one side of the Atlantic, European regulators developed and implemented a feasible biosimilars pathway by the mid 2000s, with regulation in place by 2003 and the first products being approved and sold in 2006. As such, there has now been over a decade of experience with biosimilars in Europe (and Australia which permitted biosimilars entry conditional on the European approval process). In the United States, in contrast, the development and implementation of a feasible regulatory pathway was long delayed. The legislative approval for a biosimilars pathway ultimately came as part of the passage of the Patient Protection and Affordable Care Act of 2010, ushering in a lengthy process for the development of a feasible regulatory approval pathway. The first biosimilar was approved in the United States in 2015, and appeared on the market in late 2015. ${ }^{1,2}$

\footnotetext{
${ }^{1}$ Sandoz's Zarxio, which is a biosimilar of Filgrastim, a drug for neutropenia was approved by the U.S. Food and Drug Administration on March 6 $6^{\text {th }}, 2015$ but was not sold on the market until the third quarter of 2015.

${ }^{2}$ Though not the primary focus of our analysis, the long delay in the development of a practical biosimilars regulatory pathway may reflect a significant level of regulatory capture and influence, insofar as pioneer manufacturers have significant incentives to delay the introduction of competition relative to the incentives of the biosimilars manufacturers to engage in the development of rules that would create the potential for market competition.
} 
This divergence in the timing of the establishment of regulatory pathways for biosimilars motivates the primary research question of this paper: what might we learn from the European experience with biosimilars in order to inform future policy design and institutional choices for both the United States and Europe? $?^{3}$ For example, some experts in the United States predicted that the entry of biosimilars would lead to little health care expenditure savings - either because biosimilars would not be close enough substitutes to their reference counterparts to create significant price competition, or because the high fixed cost of entering new biosimilar markets would reduce entry and, in turn, price competition (see, for example, Grabowski et. al., 2007). But potential for price savings from biosimilars (and assessments of the relative substitutability of reference drugs and biosimilars) is ultimately an empirical question, and as such, we consider nearly a decade of market experiences across 23 European countries to bring early data to bear on these conjectures.

Three interrelated features of the European experience are particularly important in shaping our analysis. First, at the time of the introduction of the first biosimilars in Europe, there was not only uncertainty about how biosimilar competition might play out, but also scientific and technological uncertainty as to whether biosimilar products would be able to be produced, distributed, and developed in a way that would ensure a consistent level of safety and efficacy for patients. ${ }^{4}$ Over time, however, these safety and efficacy concerns have largely been alleviated: in Europe, there have not been any unexpected adverse events attributable to the use

\footnotetext{
${ }^{3}$ In so doing, we build on prior work that has examined the potential for biosimilars such as Grabowski et al (2006) and Grabowski et al (2007), and papers that have examined the European experience with biosimilars (such as Rovira et. al., (2011)) and Berndt, et al (2015). As we explain below, our work moves beyond these prior analyses by undertaking a detailed empirical analysis of the role of buyer institutions in shaping differences in entry and market impact (quantity, price) across different European countries, and thus grounding our understanding of how alternative policy choices might result in different patterns of diffusion and impact in the United States.

${ }^{4}$ Unavoidable, minor molecular differences between reference drugs and biosimilars (e.g. glycosylation patterns) may increase immunogenic responses or reduce clinical efficiency in ways that are unpredictable.
} 
of biosimilars over the period from 2006 to $2015 .{ }^{5}$ In other words, while the precise rules governing the production of biosimilars in the United States are separate from those in Europe, the resolution of scientific uncertainty over the past decade implies that the adoption of biosimilars will be shaped by economic and institutional factors rather than as a result of meaningful differences in health outcomes arising from use of the original formulation versus a biosimilar product.

Second, while the regulatory approval process for all biotechnology drugs occurs through the European Commission (EC) based on the recommendations of the European Medicines Agency (EMA) - the scientific and regulatory body that evaluates products sold in the European Union (EU) - market entry of individual products occurs subsequently on a country-by-country basis. ${ }^{6}$

As a result, rather than simply providing a broad comparison of the experience of different drugs, we are able to undertake a detailed empirical analysis at the drug-country-year level that leverages differences across countries in the timing of entry and nature of drug procurement institutions.

Third, not simply a matter of country-level fixed effects, we take advantage of a potentially important and underappreciated source of differences across countries: variations both within and across countries and over time - in procurement institutions. For example, one of Poland's national-level drug tenders, was not introduced 2012 although the biosimilar (Somatropin) first entered the Polish market in 2008. Because the 2012 procurement policy update affected only one drug, we can better identify the impact of the procurement policy

\footnotetext{
${ }^{5}$ Cutroneo et al (2014) "Safety Profile of Biological Medicines as Compared with Non-Biologicals: An Analysis of Intial Spontaneous Reporting System Database” Drug Saf (2014) 37:961-970; Vermeer, Niels (2012) "Traceability of biopharmaceuticals in spontaneous reporting systems" European Medicines Agency, presentation. Vermeer, Niels et al (2013) "Traceability of Biopharmaceuticals in Spontaneous Reporting Systems..." Drug Saf (2013) 36:617625. GABI "No relevant difference in ADRs from biosimilars and originators" posted 10/01/2015

${ }^{6}$ All biotechnology drugs (whether original or biosimilar) must be approved through the EMA. Some (non-biotech) biologics may use another regulatory pathway, but those products do not appear in this study
} 
change on market outcomes at the same time as we control for country-level effects. While most discussions of the potential for biosimilars compare broad differences across countries in terms of overall market size or income per capita (a model which would suggest that Southern European countries such as Greece and Italy should be some of the earliest adopters of biosimilars), our research highlights differences across countries in their buyer institutions as a separate and potentially important force influencing entry, pricing, and take-up.

A number of researchers have examined the impact of procurement institutions on price discrimination in the pharmaceutical industry (e.g. Danzon and Chao, 2000). Price dispersion is of course partially due to income differences, however, procurement institutions also matter to price formation, as shown in Duggan and Scott Morton (2010). ${ }^{7}$ If prices are formed through negotiation or a bargaining game, then both parties' outside options matter. If the buyer can set up institutions in its country to make the outside option of the pharmaceutical manufacturer worse, then it can obtain a better contract. If prices are set in response to elasticities, a government could alter institutional design in a way that causes the buyer(s) to become more price elastic: optimal price declines in response to increased buyer elasticity.

The empirical work in the paper combines IMS product-country-year-level data for the first three classes of biosimilars approved in Europe (biosimilars for reference drugs Epoetin, Filgrastim, and Somatropin) with a novel policy survey that allows us to capture granular differences in European biosimilar buyer institutions across 23 countries over the years 20072014. We use these data to document three broad findings. First, we show there is significant and striking variation in the entry and take-up of biosimilars across otherwise similar countries (i.e., countries that are similar in terms of GDP per capita or measures of overall health care

\footnotetext{
${ }^{7}$ See also Price Discrimination in Input Markets (Inderst and Valetti, 2009).
} 
spending). Larger markets attract more entry, reflecting expected patterns and economic incentives (Acemoglu and Linn, 2004; DuBois, et al., 2015). Further, for a given drug, the rate of biosimilar penetration (relative to a country's initial sales of biologic reference product) can vary by an order of magnitude. The effects are strongest in the Epoetin and Filgrastim markets, which have the highest number of entrants and the highest revenues. Second, we draw on our original survey of procurement and purchaser institutions at the country level (and to a limited extent, within country, over time) to undertake an exploratory evaluation of some of the reasons for these large differences. Our evidence suggests that the strength of incentives in the procurement process are critical to understanding the penetration of biosimilars and cost savings from their use. For example, we find that on average, going from no formal tendering to a "winner-takesall" process of competitive tendering is associated with an additional 14.6 percentage points of biosimilar take-up.

Finally, we undertake a simple counterfactual analysis highlighting the cost savings achieved through biosimilars in Europe, and, perhaps more importantly, the potential cost savings that might be achieved in the presence of strong demand-side institutions. While rough, our estimates suggest that the introduction of biosimilars likely resulted in savings of around $\$ 1.5$ billion U.S. dollars in our sample during the early years of biosimilar competition that we observe in our data.

Our analysis offers several implications for policy both in the United States and abroad. Prior to this work, a small literature had suggested that the prospects for cost savings from biosimilars was likely to be modest: high fixed and marginal manufacturing costs would likely limit the number of entrants, and limited substitutability would reduce the potential for diffusion (at least compared to traditional generics approved under Hatch-Waxman). On the one hand, our 
analysis provides support for some of the contentions of this earlier literature: there are only a limited number of entrants per country, and, even when diffusion is successful, it is more likely to take several years to observe increases in use, rather than a large wave of adoption immediately after the first instance of biosimilar approval. At the same time, our data show much more adoption of biosimilars and related cost savings than biologic innovators predicted would occur.

Our analysis highlights a central role for buyer institutions in shaping the ultimate attractiveness of these markets for biosimilar manufacturers. In particular, buyer institutions such as tenders can significantly enhance the potential for biosimilar penetration while also helping to realize significant cost savings for health care systems. Both the fact of less penetration than small molecules, and the strong role for buyer institutions, are driven by the regulatory framework that requires biosimilars be prescribed by a physician (rather than having interchangeable status at the pharmacy). Biosimilar policy that lowers prices in the United States (and doesn't just add another product to the market) therefore either requires interchangeability or purchasing policies at the federal, state and private level that facilitate price competition between biosimilars and innovator biologics.

The remainder of this paper proceeds as follows: Section 2 provides background on biologics and biosimilars and concludes with a short introduction to the development of a biosimilar pathway in Europe (and Australia). With this background in mind, we then consider the underlying economics of biosimilars, highlighting both traditional industrial organization factors such as the fixed costs of entry as well as the role of demand-side institutions such as procurement policy in Section 3. Section 4 introduces the data, including our original survey of 
county-level buyer institutions. Section 5 presents our main results, and Section 6 considers policy implications and directions for future research.

\section{BIOLOGICS AND BIOSIMILARS}

\subsection{The science of biologics and biosimilars}

Biologics, also called biopharmaceuticals or biologic drugs, are a broad class of products including blood-derivatives, vaccines, somatic cells, gene therapies, and recombinant therapeutic proteins. Biologics are typically derived from or produced by mammalian cells or microorganisms and typically require expensive, technology-intensive manufacturing involving biological processes. ${ }^{8}$ In contrast to small-molecule drugs that involve chemical synthesis with molecular masses - called a "Dalton weight" - of only a few hundred, most biologics are large, complex, and heterogeneous proteins with molecular weights ranging from 6,000 to 150,000 Daltons (e.g. monoclonal antibodies) that can only be produced using biological processes.

As a result of their biologically-derived nature and complexity, biologic products are not produced at scale through traditional chemical engineering but rather through biological manufacturing. Though there are a number of approaches to biological manufacturing, a typical approach involves creating and culturing genetically altered cell lines to produce specific therapeutic proteins that are then processed and packaged into a form that can be delivered into a human patient. The organic and complex nature of this process makes the characterization and manufacturing of biologics significantly more challenging than producing traditional smallmolecule drugs (MacNeil and Douglas, 2007). For example, changes in the medium,

\footnotetext{
${ }^{8}$ According to the FDA, drugs classified as biologics may be composed of molecular structures ranging from sugars to proteins to nucleic acids - or a combination of these substances - and may also include living cells or tissues (http://www.fda.gov/AboutFDA/CentersOffices/OfficeofMedicalProductsandTobacco/CBER/ucm133077.htm)
} 
temperature, timing, and equipment materials used in processing can all affect the nature of the product, rendering the manufacturing process highly sensitive and complex and necessitating extensive in-process controls.

Until recently, the ability to characterize the molecular equivalence between two biologics produced by similar processes was problematic and at the same time, natural variation arising from the process of reproduction of any biological substance implies the presence of tiny, but discernable differences in the protein produced - even across two samples of the same product produced on the same production line. The combination of complexity and biological origin has an important implication for the design and implementation of a biosimilars regulatory regime: follow-on biologic manufacturers cannot produce an exact copy of a biologic at the level of its molecular structure.

\subsection{Biologics development and the market for biologics}

The development and commercialization of new biological entities (NBEs) involves considerable cost and uncertainty. As with small molecule drugs, development times for new biologic therapies are quite long - typically over a decade - and the combined costs of development activities are high. While biologic drug development costs are likely comparable in magnitude to estimates of the cost of developing new chemical drugs (DiMasi and Grabowski, 2007), the composition of these costs are somewhat different: on average, biologic drug development is characterized by higher discovery and preclinical expenditures, longer average pre-clinical trial development times, higher costs associated with process engineering and manufacturing, but shorter subsequent clinical trial times (Grabowski, 2008; Grabowski et. al., 2006). 
A significant driver of these differences is inherent to the nature of biologics products. A number of distinctive sources of risk and cost stand out. First, as complex biological materials, biologics' effects in humans are hard to predict and somewhat variable; as a result, there is considerable uncertainty and requisite optimization of the formulation and dosing of biologic drugs. Further, relative to the more straightforward process of manufacturing scale-up for traditional pharmaceuticals, considerable investment and uncertainty is expected in the process of scaling up manufacturing and resolved along the way. Small changes to bioprocessing can impact biologic drugs' clinical attributes in unpredictable ways: for example, small changes in the precise methods by which the cell lines that produce a biologic are prepared can have significant effects on the product that is produced, rendering process optimization and quality control central elements of the commercialization process (Kozlowski et al., 2011). Finally, delivery systems for biologics and chemical drugs also frequently differ: while most chemical drugs are oral agents and can be distributed through retail and mail-order pharmacies, biologics are often injectable or infusible products, and are typically administered by a health care provider in a hospital, a clinic, or a physician's office. ${ }^{9}$

Despite these challenges, biologics represent a significant and growing share of global pharmaceutical spending; worldwide revenue from biologic drugs quadrupled from US $\$ 46$ billion in 2002 to over US\$200 billion in 2013. Although biologic drugs account for less than $1 \%$ of all U.S. prescriptions dispensed, their sales amount to roughly $28 \%$ of all prescription drug spending, with both use and cost expected to grow over the coming years (Sarpatwari, Avorn, and Kesselheim, 2015). The prices of biologics are typically high due to a combination of factors

\footnotetext{
${ }^{9}$ However, a few self-injectable products, including insulin and some growth hormones, may also be dispensed through pharmacies, with country-specific regimes: for example, in Spain, growth hormone is dispensed in hospital pharmacies, but insulin and Interferon-alpha are dispensed in retail pharmacies.
} 
including high manufacturing costs and disease severity (and as a result inelastic or less elastic demand). For example, Lumizyme (alglucosidase alfa), an orphan drug for the treatment of Pompe Disease, costs approximately $\$ 100,000$ per year for children and $\$ 300,000$ per year for adult treatments.

These high prices can be maintained for several reasons. First, the patient is often insured and therefore has inelastic demand. Second, many manufacturers provide financial assistance to patients who would otherwise not be able to afford the full price or the (often 30\%) co-pay of a drug costing thousands of dollars a year, again contributing to inelastic demand. Thirdly, it is frequently the case that any given insurer has very few patients (e.g. perhaps 2) who need a particular expensive biologic, so the buying institution may not focus its resources or managerial attention on seeking out a lower price.

But importantly, persistently high prices also reflect limited competition on two dimensions: first, many biologic drugs are the only product for a given disease and therefore do not face price competition from (even weak) substitutes. Secondly, the FDA has been so slow in creating a biosimilar pathway that innovator biologics in the United States have effectively had market exclusivity even when the relevant patents have expired. For these reasons, competition policy concerning the entry and procurement of biosimilars is particularly important.

\subsection{The Biosimilar Pathway}

Given the high prices and lack of substitutes for many biologics, policymakers and health care financing agencies could save society considerable costs by developing policies that would facilitate entry of biosimilars after relevant patents expire. Physical differences between biologics and small molecule drugs mean that the standard generic drug entry pathway cannot 
ensure that entering biosimilars are safe and efficacious. Existing pathways were for generic versions of chemically manufactured, small-molecule drugs. The entry requirements are simpler -- based on pharmaceutical equivalence and bioequivalence which can be determined with precision using standard chemistry assessments. ${ }^{10}$ In the case of biologics, however, regulators had to write different regulations to account for both product heterogeneity and lower product stability. Approved biosimilars match the variability of the reference biologic and the structural attributes, with biological functions and human pharmacokinetics and pharmacodynamics that are highly similar but not identical.

The European Medicines Agency (EMA) is responsible for regulating biologics and other drugs for the European Economic Area (EEA). ${ }^{11}$ When the European Medical Agency (EMA) began to discuss a biosimilar approval pathway in the early 2000s, there was significant uncertainty as to whether the regulatory pathway would in fact be established, whether entry would occur once it was established, and what the price and accessibility impacts would be conditional on market entry. A key milestone occurred in 2003 when the EMA laid out a more detailed framework establishing the precise requirements of and potential for a biosimilars pathway. For all products submitted for approval after October 30, 2005, the safety and efficacy profile of the biosimilar to a reference product would be established by the EMA for all EU countries simultaneously following the expiration of the reference product's so-called "data

\footnotetext{
${ }^{10}$ When developing a generic, a firm can both synthesize the same chemical compound and carry out analytical studies to confirm its molecular identity. Once this has been demonstrated, a bioequivalence study in humans is sufficient to prove therapeutic equivalence. This is achieved through a comparative bioavailability (pharmacokinetic) study that shows that the rate and extent to which an active substance is circulated is equivalent in both drugs. Once established, it can be assumed on scientific grounds that both the original and generic candidate products will share the same safety and effectiveness profile.

${ }^{11}$ The EMA's process results in a single marketing authorization that is valid in all EU countries as well as in the EEA countries Iceland, Lichtenstein, and Norway.
} 
exclusivity" period. ${ }^{12}$ After this time, biosimilar entrants are able to use the findings and clinical indications obtained by the reference product in submitting regulatory documents to the EMA. This centralization at the EMA was notable insofar as chemically-synthesized generics had historically been approved by individual country regulators, but consistent with the regulation of all European biotechnology products at the EMA level.

However, relative to small-molecule generics, the regulatory requirements and approval standards for biosimilars are still significantly higher. These include quality, comparability, and results from head-to-head pre-clinical and clinical studies to demonstrate comparable safety and effectiveness. Guidelines concerning the nature of scientific data that may be used to substantiate a claim of "similarity" are issued by the EMA's Committee for Medicinal Products for Human Use (CHMP). Depending on the structural and functional complexity, the therapeutic indications, and the regimen of the biologic serving as the reference medicine, requirements may vary for proving product comparability and subsequent safety and efficacy. ${ }^{13}$ Table I of Appendix C lists the legal requirements for a new biosimilar application to the EMA.

In 2010, four years after Europeans had biosimilars available on the market, the U.S. Congress instructed the FDA to create two pathways for approval of biosimilars. The first is the biosimilar standard described above that ensures the follow-on product is sufficiently similar that it can be used to treat the same condition. The biosimilar carries the same molecular name, however, patients must be switched between the reference product and a biosimilar (or between

\footnotetext{
${ }^{12}$ Under this regime, both new chemical entities (NCEs) and new biologic entities (NBEs) are granted ten years of market exclusivity with potential for one-year extensions if new therapeutic indications are authorized.

${ }^{13}$ The specific requirements for a biosimilar Marketing Approval Application dossier are articulated in Annex I to Directive 2001/83/EC and must satisfy the technical requirements of the monographs of the European Pharmacopoeia and any additional requirements (e.g. those defined in relevant CHMP guidelines).
} 
biosimilars) by a physician. By contrast, the FDA defines an "interchangeable biological product" as one that is "biosimilar to an FDA-approved reference product and meets additional standards for interchangeability." ${ }^{14}$ An interchangeable biological product may be substituted for the reference product by a pharmacist without the intervention of the physician. The interchangeable standard has no final FDA guidelines at the time of writing, nor any approved products.

\subsection{European Biosimilar Regulation}

The value of establishing a biosimilar pathway is only realized if biosimilars meaningfully enter existing drug markets, decreasing average prices paid for medicines and/or expanding patient access. Most countries (as well as states within the United States) allow a pharmacist to move a patient to an $\mathrm{A} / \mathrm{B}$ rated small-molecule generic drug - or between different generics - without permission from the physician. There is little risk associated with this type of pharmacy substitution as the active substance is identical and the treatment regimen is the same. Many European countries have expressed opposition to substitution by pharmacists. For example, Spain maintains a no-substitution policy for all biologics - i.e. even among two original products bearing the same product name such as different insulins. This, of course, serves as an effective ban to the dispensing of a different biologic drug than the one prescribed by the physician. In our data, pharmacy substitution was only flagged as being allowed in one

\footnotetext{
${ }^{14}$ Importantly, the European Union uses the same two terms, but gives them opposite definitions, with "substitutability" indicating the ability for pharmacist substitution. In Europe, each country could by and large shape their own policies regarding "interchangeability" (where clinicians could use a biosimilar to achieve the same clinical effect in the same patients) and "substitution" (where pharmacists could replace one version of a biologic with another without having to consult the prescriber. health care provider who prescribed the reference product." (http://www.fda.gov/Drugs/DevelopmentApprovalProcess/HowDrugsareDevelopedandApproved/ApprovalApplicat ions/TherapeuticBiologicApplications/Biosimilars/)
} 
country-year (France in 2014), but it was not done in practice, given previous laws complicating the question of whether it was actually permitted. ${ }^{15}$

While the product authorization decision for all new biologic drugs (biosimilar or not) occurs at the EMA level, prices and procurement policies are determined at the country (or regional/state) level, leading to significant variation in realized entry and take-up of new biologic products across European countries. All the countries in our sample have national health provision; to be included in the set of drugs paid for by the government requires authorization which includes a negotiation over price. Countries have various ways of negotiating these prices which we detail below.

The first three classes of biologic drug markets to experience European biosimilar entry were Epoetin, Filgrastim, and Somatropin and form the basis of our empirical analysis. Epoetin, ${ }^{16}$ stimulates red blood cell production in the body and is frequently used in dialysis patients; Filgrastim, stimulates the bone marrow to produce neutrophils, a type of white blood cells (and is typically used after chemotherapy); Somatropin is a human growth hormone. As highlighted in Table 1, though the biosimilar drugs in our sample were initially introduced into the EMA over a 5-year period, there was significant heterogeneity in the extent of their entry both across and within countries (Figure 1). For example, in 2014, Finnish patients received 99.6\% biosimilar Epoetin by volume vs. French patients, who received 23.9\% biosimilar Epoetin by volume. Yet within Finland, take-up rates of other biosimilars were lower, with biosimilar

\footnotetext{
${ }^{15}$ France adopted a law regarding substitution of biosimilars for naïve patients, however the law did not have an implementing decree and therefore did not come into force during the period studied here. The French Agency updated their position in May of 2016 to allow for interchangeability under conditions of patient transparency, monitoring, and traceability of biosimilars.

${ }^{16}$ There are slightly different versions, or generations, of Epoetin on the market in Europe: original biologics exist for both Epoetin Alpha and Epoetin Beta. Notably, only biosimilars to Epoetin Alpha have been developed; there are no biosimilars to Epoetin Beta. The biologic Epoetin Zeta only exists in biosimilar form and takes Epoetin Alpha as its reference product. We consider the Alpha and Zeta forms of Epoetin as one combined class in our analysis, since they are approved by the EMA for the same set of indications and used interchangeably in a medical setting.
} 
Filgrastim comprising $59.1 \%$ and biosimilar Somatropin comprising $37.9 \%$ of the domestic market by volume.

While this brief description captures the main elements of the setting for our analysis, it is also useful to note a few caveats: first some parallel imports exist and their use is known to impact pharmaceutical firms' entry strategies (Kyle, 2007). Parallel imports are drugs purchased in a low-price country such as Greece, and sold in a country with relatively high prices such as the UK or Belgium; this arbitrage is permitted under EU free trade rules. We searched the EU's parallel import database ${ }^{17}$ for cases of our drugs being arbitraged. The data indicate that the impact of parallel imports was very limited in the countries and years that we study: only 3 products in our sample (Omnitrope, Binocrit, and Retacrit) had any parallel imports at all and these products were almost exclusively imported to Germany only. ${ }^{18}$ Another interesting aspect of our dataset is the inclusion of data from Australia, which has an explicit policy of piggybacking on EMA decisions regarding biosimilars (see Appendix A). ${ }^{19}$

\section{THE ECONOMICS OF BIOSIMILARs: ENTRY, PRICING, AND BUYER INSTITUTIONS}

To evaluate the economic content of the European experience with biosimilars, it is important to emphasize that, once the EMA has approved a biosimilar, there is a separate set of decisions for each distributor as to whether to enter each country-specific market or not. In other words, while biosimilar approval takes place at the EMA level, the strategic choice of whether to

\footnotetext{
17 https:/ / fmapps.emea.europa.eu/paradist

18 The only exception is that Retacrit was also imported to Austria in 2014. Omnitrope had the most country-years of parallel imports and was imported to Germany in most, but not all sample years. Binocrit was imported to Germany in three non-consecutive years and Retacrit was imported only in 2014.

${ }_{19}$ Our empirical results are not affected by the inclusion or exclusion of Australia from the analysis sample.
} 
enter each market governed by the EMA approval process is a firm-level choice. Both the likelihood and extent of such entry will of course depend on the potential profitability of that country's market, and these profits, in turn, depend on the expected quantities and prices that entrants anticipate at the time they are undertaking their entry decision.

\subsection{A simple model of entry}

To fix ideas, it is useful to consider a simple entry model (along the lines of Bresnahan and Reiss (1991) and Berry (1992)) as adapted to the pharmaceutical context by Scot Morton (1999) examining the entry decision of traditional generics in the United States. In these models, the marginal entrant compares the profits accruing from entry (given the anticipated competitive structure and the anticipated equilibrium number of entrants) against a (perhaps idiosyncratic) sunk entry cost. In this setting, entry is more likely in larger markets and where fixed costs are lower. More entry means a larger number of firms competing and lower prices, ceteris paribus.

Using this baseline model, biosimilar entry is likely also to be impacted by the underlying cost structure and the degree of regulatory-induced and technological product differentiation. The number of manufacturers will be increasing as clinical testing and entry costs fall and will be decreasing with restrictions on product use. To the extent that products are viewed as clinically differentiated, price competition will be softer and prices will be higher as a result.

We extend the basic framework by also incorporating explicitly the role of drug procurement and associated policy incentives. Because European health care is predominantly public (either in its provision or funding), the buyer of biosimilars, will be a non-profit regulated entity, like a hospital or a regional authority, or a government. This buyer is distinct from, for example, a for-profit insurer that might be the purchaser of the biosimilar in the United States. In 
particular, we need to identify the economic incentives of a regional authority or hospital to purchase biosimilars.

The economics literature includes work on the motivations of a regulated entity to purchase the lower cost input. An important distinction is between cost-plus regulation and fixed-price. In a cost-plus setting, the hospital (or other procurement institution, e.g. a state or region) would be paid the costs it incurs to treat all the patients who arrive in a given time period. The manager of such a system would experience no budgetary difference between using the reference biologic and a less expensive biosimilar, because its costs are fully paid in either case. In contrast, under a fixed-price system, the system would be paid some amount for a procedure or diagnosis and would subtract its costs from that revenue to determine its surplus.

The classic work of Averch and Johnson (1962) examines a setting in which the regulator (health ministry) has imperfect information concerning next year's cost and cannot perfectly instruct the regulated firm (hospital) how to choose inputs. The managers of the firm have preferences not to exert effort, though effort reduces subsequent costs. For example, creating and running an effective tendering process for biologic drugs at the hospital would require effort but lower costs. As in Laffont and Tirole (1993), the regulator does not know the benefit of creating a tendering process, while the managers of the hospital do. However, if the regulator pays the firm a fixed price contract, then managers will exert effort to lower costs up to the point where marginal disutility of effort is equal to the marginal utility from the cost savings. This effort might include setting up a tendering system and convincing the clinicians in the system to use the winning product.

In this study we focus on the impact that the choice of regulatory design has on biosimilar price and quantity in our set of markets. The impact of competition could appear in 
price, quantity, or both. For example, if a biosimilar bid were used to create competition for the reference biologic, but then hospitals never actually purchase the biosimilar because the reference price manufacturer lowers its price, prevailing prices in that drug market would be lower as a consequence of the tendering, while biosimilar sales could still be very low. On the other hand, a tendering process could result in limited price competition on the part of the reference biologic and therefore a high market share for the biosimilar.

Many national health systems create an official drug list in which the center approves a product to be included on the list at a particular price. The national health system pays for drugs on the list and physicians prescribe off the approved drug list. The drug's negotiated price may vary depending on the center's bargaining power. However, regardless of that price, national demand will not be elastic under a 'list' system because there is no way for the manufacturer to sell more product by setting a lower price. Schemes such as reference price groups - where consumers pay the residual cost above the lowest cost product in the group - do create elasticity. Likewise, a competitive tender by the hospital, region, state, or insurer (sickness fund) also creates elasticity.

Consider the following simple market structure: one biologic firm that produces a reference product (firm 1) faces post-patent entry from a biosimilar manufacturer (firm 2). The biosimilar firm faces unit production cost $\mathrm{c}$ and will enter the market when expected profits are positive. In a single period model, with differentiated Bertrand competition, firm 2 thus considers its expected profits from market entry as:

$$
\pi_{2 i}=\left(p_{2}-c\right) D\left(p_{1}, p_{2}, \beta_{i}\right)-F_{i}
$$

where $\beta_{i}$ indexes the nature of price competition in country i and $F_{i}$ summarizes the fixed cost of entry into distribution in a particular country. In this model, how a national health system 
procures a biosimilar, $\beta_{i}$, is a policy choice of regulators. Notably, $F$ may also be affected by local regulators and/or policy makers (but is not the fixed cost of getting a molecule approved by the EMA, which has already happened). We consider the impact that the choice of policy design ( $\beta$ ) has on biosimilar take-up, quantity sold, and prices in our set of markets.

\subsection{Empirical Model}

Our empirical analyses relate the outcomes of interest, price and biosimilar penetration, to measures of the market and policy environment. The measures we include capture the overall impact of policies on both the supply side (entry) and demand side (procurement). In the analyses that follow, we consider entry by distributors and producers (Table 5), changes in prices (Tables 6 and 7), and biosimilar penetration, as measured by share of total sales (Table 8). We estimate equations of the following form:

$$
Y_{d c t}=f\left(\alpha+\text { BPolicies }_{d c t}+\gamma_{1} \delta_{d}+\gamma_{2} \rho_{c}+\gamma_{3} \lambda_{t}\right)+\epsilon_{c}
$$

Where $Y_{c t}$ represents outcome $\mathrm{Y}$ for drug class d, in country $\mathrm{c}$, in year $\mathrm{t}$ and $\beta$ represents a vector of coefficients on various policy variables such as quotas, tenders, tender strength, and other non-procurement incentives to use biosimilars. In these specifications, $\delta_{d}$ is a drug class fixed effect, $\rho_{c}$ is a set of country-specific variables, and $\lambda_{t}$ is a time trend or set of year fixed effects. $\epsilon_{c}$ is an error term, clustered at the country level. We model distributor/product entry using Poisson models, as indicated by the use of count variables, and prices and penetration using linear regression models. Although direct causal interpretation of these coefficients is not possible in this setup, we believe that the results are valuable, as they represent, to our 
knowledge, the first quantification of the relationship between demand-side factors and subsequent entry, prices, and penetration.

\section{DATA}

\subsection{EuROPEAN APPROVALS}

Over our period of observation, 15 unique biosimilars were approved ${ }^{20}$ for use and sold in Europe and Australia. ${ }^{21}$ Table 1 lists these biosimilars by date of approval and provides detail on each product's class, international product name, and clinical indications. As seen in Table 1, the EMA may recommend authorization of multiple biosimilars on the same date, or approval recommendations may be staggered over time.

The identity of a biosimilar entrant, as well as the manufacturer(s) of the biological active substance and the manufacturer(s) responsible for batch release, must be authorized at the time of approval. We are therefore able to use the EMA's official documents to construct a complete picture of authorized biosimilar entrants in Europe..$^{22}$ A potentially confusing aspect of the manufacturing data is that the firm name on the drug label - the distributor - and authorized entrant need not be the same corporation, although they often are. In some instances, a firm separate from those listed in EMA authorization documents can be seen branding and selling a particular biosimilar. For example, consider Binocrit, an Epoetin biosimilar. The EMA entrant ("marketing authorisation holder") is Sandoz, while the manufacturers of the biological active

\footnotetext{
${ }^{20}$ As noted in Table 1, two biosimilars were approved and then subsequently withdrawn from the market by their producers.

${ }_{21}$ Appendix A describes Australian regulations, which are primarily based on EMA decisions. Therefore, we include data from Australia in our regression estimates, however excluding Australia does not impact our results. While Australia recognizes the EMA's decisions on biosimilars, the reverse is not true.

${ }^{22}$ All documents are available athttp://www.ema.europa.eu/
} 
substance are Rentschler Biotechnologie GmbH (Germany) and Lek Pharmaceuticals d.d.

(Slovennia), but the manufacturer of the biologic product is Sandoz, and the distributor in

Germany is Eruimpharm. In addition to considering manufacturers, we consider distributors of biosimilars, who, as noted, may be different parties. Table 1 lists countries of market entry and the total number of distributors of each biosimilar and Figure 3 shows the number of distributors relative to the number of approved products in our full sample: we observe a substantial amount of entry by biosimilars across markets and drugs. ${ }^{23}$

We focus on two primary measures of entry into new biosimilar markets: 1) the identity of unique distributors - i.e. the firms under whose names the drugs are sold; and 2) the identity of unique product entrants - i.e. the firms that have successfully pursued and been granted marketing authorization from the EMA for a biosimilar (a.k.a. the "marketing authorisation holder"). Price competition may occur at the country level among distributors, but such distributors also face a (potentially common) marginal cost, which would be set by the product entrant. We consider both entry measures in our empirical analysis.

\subsection{BiOSIMILAR SALES}

We obtained data from IMS Health (MIDAS ${ }^{\text {TM }}$ Database) on U.S. dollar revenues and quantities sold (reported in standard units) of all biologics in 22 European countries plus

\footnotetext{
${ }^{23}$ Notably, the two lines may cross and one need not be above or below the other. When the total number of EMAapproved products is greater than the number of unique distributors in the sample, this indicates that either some products are not distributed at all or that the number of distributors that are active in our sample countries in a given year and class of biosimilars is smaller than the total number of approved biosimilars in that class. This will be the case, for example, if a single distributor is responsible for the distribution of more than one biosimilar product within a class of drugs. More commonly, we see that the number of distributors active in our sample is greater than the number of approved products. This is the case when one product uses different distributors in different countries or when one product is sold by multiple distributors within a country.
} 
Australia. We use these data to calculate the average local currency price per standard unit of each drug. ${ }^{24}{ }^{25}$ Based on the prices reported to IMS, we create average prices for the reference product, for biosimilars, and a weighted overall average price for each year, biosimilar drug class, and country in the dataset. ${ }^{26}$ In analyses, we subsequently convert dollar prices into local currency and calculate changes in price in local currency terms. This eliminates any noise created by fluctuations in the dollar vs. local currency exchange rate and is appropriate because drug procurement contracts are expected to always be negotiated in local currency terms.

Appendix C, Table II tabulates the data by country and shows the first year each class of biosimilar was sold in each of the countries in our sample. The years covered are 2007 to 2014, inclusive. ${ }^{27}$ The data include a flag for biologic product type: reference product or biosimilar. We carefully examined and cleaned the data and corrected minor inconsistencies in biosimilar vs. other biologic product categorizations, but found no significant errors in the classification of products. ${ }^{28}$ Table 2 presents total U.S. Dollar sales of biologics and biosimilars by class and year. We create two relative price variables for biosimilars as follows. Our first measure takes the (local currency) reference product price in either the first year of the data (2007) or the year

\footnotetext{
${ }^{24}$ We calculate prices in local currency since procurement contracts are likely to be negotiated in local currency rather than U.S. dollar terms. In robustness tests, we confirmed that using U.S. Dollars produced similar results with respect to predictors of price changes.

25 The biologic drugs we consider are produced in several different forms. For example, we see different packaging options that reflect the number of milliliters of liquid in a pre-filled syringe. We combine all forms of a drug sold by the same firm in the same country and year into one observation, scaled by standard units of active drug. We can do this very accurately because IMS provides a variable called "standard units" which converts each form of every biologic product into common units. Other researchers have used standard units from the IMS data to capture quantities sold (e.g. Berndt and Trusheim, 2015). Alternative volume measures include defined daily dosage (DDD), extended units, and so-called "eaches." We follow Berndt and Trusheim (2015) in using standard units.

${ }^{26}$ Other researchers (e.g. Ganslandt and Maskus, 2004) have written about the role of parallel imports in European pharmaceutical Markets. Such imports are legal and happen frequently. They are, however, less likely to be relevant in the setting we study, since biologic drugs are relatively costly and often procured by health systems for administration in hospitals.

27 There are four exceptions to this: due to lack of full data availability, data for Lithuania, Slovakia, and Sweden are only included through 2012 and data for Latvia are only included through 2010.

${ }^{28}$ Other researchers should be aware that IMS creates a price by dividing revenues by quantities, but then reports a rounded quantity. Re-creating price by dividing revenue by the rounded quantity results in large price outliers when quantities are small. It is possible to reconstruct the non-rounded quantity by dividing revenue by price again.
} 
immediately prior to biosimilar entry (whichever is later) as the benchmark reference biologic price; this becomes the denominator of our relative price variable in all future years. We denote innovator $i$ 's price in country $c$ at time zero, $P_{i c t_{0}}$. The price of biosimilars sold in that country, $c$, in each subsequent year, $t$, is the numerator. There may be multiple distributors of biosimilars, $s$, in which case we take a weighted average of their prices each year. For each of our three drugs in the sample:

$$
\text { (3) } \quad P 1_{c t}^{\text {relative }}=\frac{\frac{\sum_{s} q_{s c t} p_{s c t}}{\sum_{s} q_{s c t}}}{P_{i c t_{0}}}
$$

Thus, if only one biosimilar enters and does so at $80 \%$ of the pre-entry reference product price, the relative price will be 0.8 . If a second entrant sets a price of $60 \%$ of the original reference product price and has equal standard unit sales to the first biosimilar entrant, the weighted average relative price will be 0.7 . If the reference product matches the biosimilar price in subsequent years, our ratio will not return to one. This is desirable because both products' prices are lower than the initial reference product price due to biosimilar entry.

We also consider the average market price for a biologic drug class in a given year relative to the average market price in the year before biosimilar entry (again, in local currency terms). This is defined similarly, however the numerator includes weighted average prices of all products and distributors in a given drug class, $a$, not just the weighted average price of biosimilars in that class:

$$
\text { (4) } \quad P 2_{c t}^{\text {relative }}=\frac{\frac{\sum_{a} q_{c t} p_{c t}}{\sum_{a} q_{c t}}}{P_{i c t_{0}}}
$$

The variable calculated in equation 3 corresponds to the overall average market savings in a given year relative to the year prior to price competition. This value is of particular interest, 
since, as noted above, the average price of the reference product may drop in response to biosimilar competition and therefore there are additional savings to the payer when buying reference product in years prior to biosimilar entry to the extent this occurs.

Prices vary over time and across countries - even for the same product from the same manufacturer - but quantities grow almost exclusively monotonically as can be seen in Appendix B, Figure II. Relative prices of biosimilars also show considerable variation, though the mean is typically below one, as we would expect (Table 3). There are a number of drug-country-year combinations where the biosimilar is much more expensive than the 2007 reference biologic. However, the quantity sold in these cases is typically extremely small. Table 4 presents reference product unit prices as a percentage of the median sample unit price in the first year of data (i.e. prior to pre-biosimilar): we observe considerable variation across countries in these reference product price levels.

Our quantity variable is a measure of penetration of biosimilars by standard unit volume (growth in biosimilar volumes over time is presented in Appendix B, Figure II). We add up all biosimilar units of a drug in a country-year to form the numerator. The denominator is the sum of all units sold in the same biologic drug class (i.e. both reference products and biosimilars) and country-year, qact. Price is not used to weight the units sold. For each of our three classes of biosimilars in our sample:

$$
\text { (5) } \quad Q_{c t}^{\text {share }}=\frac{\sum_{s} q_{s c t}}{\sum_{s} q_{a c t}}
$$

One perennial issue with pharmaceutical sales data is the potential existence of ex post rebates. If a hospital receives rebates after it purchases drugs, and those rebates do not appear on the original invoice, they will not be captured in our data. As such, it is likely that prices are sometimes overstated. We do not have any way to know for which products and in which 
countries these issues are present. Any such error will, however, likely be correlated within country, as purchasing practices are more similar within countries than across them.

When considering our reference year and biosimilar market entry, we designate the first year in which a country recorded a positive quantity for a biologic or biosimilar, respectively, as

the relevant year in our analysis. Nearly all countries have sales of reference biologics in all three classes in our first year of observation, 2007. For biosimilars, any year in which the quantity of biosimilars sold was greater than or equal to $0.05 \%$ of total units sold for that class of drugs was categorized as having biosimilar entry.

Our analysis is focused on these outcome measures as well as on the number of entrants into each country-level biologic drug market. The empirical section of the paper considers policy predictors of entry, changes in price conditional on biosimilar entry, and whether biosimilars become a significant fraction of consumption in the countries in our data.

\subsection{SURVEY AND POLICY DATA: PROCUREMENT OF BIOSIMILARS IN EUROPE AND Australia}

For each country in our sample, we collected detailed data on the manner in which each class of biologic drugs and biosimilars are purchased. Recall that the EMA approves these medications for safety and efficacy simultaneously for all of the EU, and that EMA decisions also apply to Australia. The variation across countries in entry, price, and quantity consumed thus occurs because each market has a different set of policies that govern procurement, reimbursement, and to encourage usage of biosimilars - either in general or for products from particular firms who have successfully tendered for the nation's needs.

In each country, there is typically a government agency that determines whether a new product will be included in the national health scheme, and either sets a price, a reference group, 
or some other procurement scheme for it. In a typical procedure, the pharmaceutical division of the health ministry negotiates with the manufacturer and agrees that, at a particular price, the biosimilar will be added to the list of drugs for which providers will be reimbursed. For example, the health ministry and the manufacturer might agree that the biosimilar will be priced $20 \%$ less than the current price of the reference product. Alternatively, tendering may occur at the hospital, regional, or national level, as discussed below. A critical aspect of tendering is that the quantity being bid for, and the intensity of competition, may vary across types of tenders. Winning a tender could result in simply being listed on the official drug list as described above. It might result in sales to all new patients, but not existing patients. Or it might result in exclusive supply of all the patients in the tendering unit for that time period.

After the drug is available in the country, physicians prescribe it in hospital, clinic, or outpatient settings and the government (directly or indirectly) pays the bill. Note that in the first pricing example above, the government (and therefore also the taxpayer) benefits if the biosimilar is used because it is $20 \%$ less expensive. However, it should be noted that there may or may not be any financial or organizational incentives for hospitals, clinics, physicians, or patients to use the biosimilar.

Recognizing this problem, some countries in Europe have devised procurement schemes to stimulate competition between the reference biologic and the biosimilar. Most typically, this is done by empowering an agent in the system to seek competitive bids for drugs in a certain class. For example, in England, each hospital has a budget and can procure biologics through a competitive tendering process. However, the clinicians at that hospital must be ready to use the winning product rather than competitors. If the biosimilar bid is the lowest, then the hospital has an incentive to purchase the biosimilar instead of the reference product and use the saved 
resources for some other activity. In Germany, the large state-level insurers (sickness funds) are paid in a capitated fashion. These organizations create drug formularies and negotiate for discounts; they may choose the biosimilar to be the treatment for their enrollees. These types of financial incentives and procurement schemes are likely to both push down the price of the biosimilar and increase the share of its use.

With the assistance of research assistants, we assembled documents and regulations from each country in our dataset about the nature of their domestic biologic drug procurement processes. We also conducted telephone surveys of domestic biosimilar drug procurement experts. Appendix C, Table III includes a full list of individuals and institutions who contributed to our survey and gave permission for us to include their names as references.

Determining the nature of procurement was difficult for two reasons. First, it varies by drug because the drugs studied here are distributed through different channels, e.g. hospital versus dialysis clinics vs. ambulatory distribution. Second, the official regulations do not always deliver a complete picture, and an interview is required to determine the true nature of the regulation. This problem occurs because biologics are frequently "carved out" of standard health care regulations because they are so expensive, require different handling, and are often used by a small group of patients. Further, biosimilars may be carved out of standard generic procurement policies and patient cost-sharing policies. For example, in some countries the patient must pay a copayment if she chooses to buy the reference product rather than the generic. Because biosimilars are not technically generics, they are often exempted from this type of financial incentive scheme.

In addition, there can be regulations that are difficult to interpret from the written regulations. For example, hospitals in Ireland and Belgium could procure biologics by 
competitive tendering, but until recently, they were incentivized to purchase the product with the highest list price. This was because the hospital could keep the discount for itself, and therefore wanted it to be as large as possible; discounts were often absolutely larger for more expensive products. Meanwhile, the total cost of the purchases was paid by the center. Tendering designed in this way looks similar to other tendering settings, but had the perverse effect of encouraging the hospital to choose the high-priced reference biologic. In other countries, hospitals may be officially permitted to tender under the regulations, but typically choose not to. An interview allows us to track these unusual cases.

The procurement categories used in our analysis are presented with their averages in Table 3. Tenders are common in the markets we studied; many respondents attributed this to European rules that require public tendering for all large purchases. Tendering for Epoetin occurred in $94 \%$ of country-years, tendering for Filgrastim in 93\% of country-years, and tendering for Somatropin in $87 \%$ of country-years. We learned, however, that tendering processes vary in strength. The variable "strength of tender" was defined as 0 when no tendering existed at the country-class-year level and as 1 when the winner of a tender was assigned all demand at the level of the tender in a given country, drug class, and year. An intermediate value of 0.5 was assigned for cases where the winner of a tender was only guaranteed the market of "naïve" (new patient) demand. The strongest tenders - those guaranteeing all patient demand were observed only in $53-59 \%$ of country-years.

To account for effects due to the size of a drug purchase, we created a measure of expected demand of the buyer. We imputed the average size of the tendering population by dividing the national population by the number of tendering units for a country-product-year. Thus, the size of the tendering population is equal to the size of the national population in cases 
where tendering is done at the national level. ${ }^{29}$ When tendering is done at the state or regional level, the tendering population is calculated as the average population per state or region. When tendering is done at the hospital level only, the tendering population is calculated as the average population served by each hospital. In a limited number of cases in which tendering is done at two different levels (e.g. as is the case in the U.K.), the tendering size was assigned as the value of the population served by the larger of the two units.

Finally, based on the results of our surveys of experts from various national health ministries, we collected data on non-procurement incentives to use biosimilars, such as whether there was any physician or patient education about biosimilars (for any products, at any point(s) in time), whether there were any financial or non-financial incentives for physicians to use biosimilars, and whether any domestic biosimilar effectiveness study was done, etc. These types of policies may serve to effectively increase (decrease) the demand for biosimilars by growing (shrinking) the size of the potential population of biosimilar users. These non-procurement data are summarized in Table 3. While several such policies might be implemented, the average number of non-procurement policies at the country level was quite low, at 1.3 to 1.35 policies per country-drug market-year. Finally, we collected data on national population, GDP, and pharmaceutical expenditures (both as a fraction of GDP and imputed in 2010 dollars).

Biosimilars represent a novel category of medicines, particularly in the area of cancer. We were therefore aware that countries might have altered their policies (both procurement and non-procurement related) during the analysis period. Thus, in our interviews, we explicitly included questions about changes over time. When we learned of a policy change, we record the

\footnotetext{
${ }^{29}$ In one case (Slovakia) tendering was done at the insurer level, where the national health system reported that the tender only applied to $60 \%$ of the population, so the relevant population imputation was adjusted to reflect this.
} 
first year in which that change came into effect, and include that in our dataset. For example, if a country adopted competitive tendering in 2010, its binary indicator for this tender would only be coded as "1" for years 2010 and later. Aggregate data summarizing the results of our policy survey for all country-years are shown in Table 3 . We see considerable variation in procurement policies, such as the type and strength of tendering, non-procurement incentives, and countrylevel indicators across countries and over time.

Overall national fiscal health does not seem to be strongly related to the existence of competitive tendering. To the extent that there is a correlation, it is that more fiscally healthy countries are more likely to have stronger procurement policies.

\section{RESULTS AND ESTIMATION}

The take-up of biosimilars can be seen visually in Figure 2. Much of the story is clear by inspection: quantities and dollar values of biosimilars purchased trend up across almost all countries over time. Average per unit prices are stable or trending down in most cases. There are a few cases of very high biosimilar prices relative to the reference product and many of these are likely due to the data's inability to capture ex-post rebates for certain products in certain markets. We note that some high relative prices occur in countries that purchase very small amounts, and several occur in settings where known features of the reimbursement system and/or hospital price reports may result in recorded prices that are higher than the costs ultimately incurred by payers, for reasons such as rebates.

The first set of regression models (Table 5) considers predictors of distributor and product entry at the country-drug market-year level. The dependent variable in all models is the number of unique distributors observed selling positive quantities of biosimilars by country and 
year. We see that entry of distributors increases over time and is higher for Epoetin biosimilars than for Filgrastim biosimilars or Somatropin biosimilars (the omitted category). On average, Epoetin markets have an additional 0.49 distributor entrants per country and Filgrastim markets an additional 0.18 distributor entrants per country, controlling for all other factors.

National pharmaceutical expenditures are associated with more distributor entry and are used as a control for market size in all regressions. ${ }^{30}$ This result is predicted by theory: fixed costs of entering a new market - e.g. negotiating price and conditions of reimbursement with the health authority - are likely similar across countries, but some markets are much larger in (potential) size. ${ }^{31}$

Further, we see in Table 5 that biosimilar quotas and stronger tenders are associated with more distributor entry, on average, although the coefficients are only statistically significant in the OLS models used as robustness tests. These results are consistent with what theory would predict, since both quotas and (strong) tenders serve to further increase the effective potential market size for biosimilars and should be associated with more biosimilar distributor entry.

Columns 5-8 of Table 5 present the same regression models as in columns 1-4 but the dependent variable in all models is the number of unique product entrants. As was the case with distributor entry, the number of products increases over time and is higher for Epoetin biosimilars than for Filgrastim biosimilars or Somatropin biosimilars (the omitted category). On average, Epoetin markets have an additional 0.71 products per country and Filgrastim markets an

\footnotetext{
${ }^{30}$ GDP (used in models not shown) is highly collinear with national pharmaceutical expenditures and the other coefficients are virtually identical when either control is used. In our sample, on average, a country with an additional $\$ 1.5$ trillion in GDP would be expected to have one additional distributor entrant per class of biologics.

${ }^{31}$ Country level fixed cost should not be confused with the fixed regulatory costs of scientific approval, which occur at the European level.
} 
additional 0.49 products per country, controlling for all other factors. Again, national pharmaceutical expenditures are associated with more distributor entry, as predicted by theory.

Here as well, we see that biosimilar quotas are associated with more entry; on average the use of any quota is associated with roughly 0.17 additional products in a given country's market for a given class of biosimilars. The primary difference between models predicting entry of individual products versus individual distributors as that in the case of products, the strength of the tender has a negative point estimate. This indicates that bidding at the distributor level may be an important determinant of entry dynamics in the European context.

The second set of regression models explores policies associated with the price variables represented in Equations 2 and 3 above. Table 6 uses P1, the price variable in Equation 3, to compare biosimilar prices in a given year to pre-biosimilar entry reference product prices. The Table 7 uses $P 2$, the price variable in Equation 4, to compare average market prices for all drugs in a given class of biologics in a given year to average prevailing market prices in the year prior to biosimilar entry. Columns 1-4 of Tables 6 and 7 include a time trend on the right hand side, while columns 5-8 instead controls for the number of distributors at the country level: the results from both sets of models are highly similar in magnitude and statistical significance.

For the reasons explained previously, we believe that Table 7 likely best captures the product market level savings associated with the introduction of biosimilars, although these results are slightly more conservative and we focus on interpreting these here. However, we refer to the caveats discussed above with respect to this price data: since IMS data does not capture ex post rebates, we should not be surprised that these regression models are not able to strongly predict price dynamics. These results indicate that in the IMS data, average market prices fall over time at a rate of about 3.5 percentage points per year following biosimilar entry, or 
alternatively, by about 2.4 percentage points with each additional distributor entering a domestic market. ${ }^{32}$ However, this decline is steepest in Epoetin and Filgrastim markets, where average annual price declines are roughly 3.7-6.6 and 7.2-7.8 percentage points, respectively. Considered alone, there is no statistically significant time trend in prevailing average market prices for Somatropin, although the point estimate is also negative. This is consistent with only a small decline in prices for this class of biosimilars, where there have been few entrants. The price declines associated with biosimilar competition also appear to have been greater for Filgrastim relative to Epoetin and Somatropin. ${ }^{33}$ In some specifications, the presence of a quota is associated with higher prices, on average. We are concerned that while quotas and tenders may lead to lower negotiated prices, they also involve ex post rebates, which we do not observe in our data. If some country-year-drugs have this relationship, then it will create a spurious positive correlation between tendering and high prices.

In Table 7, we find that the number of entrants into a class of biosimilars is weakly negatively correlated with our measure of price. This raises the possibility that countries with relatively high drug prices may attract more product entrants. If countries with higher overall price levels have more product entry, we should control for whether a market was "expensive" prior to biosimilar competition. In alternative specifications (not presented) we also instrument for the number of product entrants in each class of biosimilars using the average price level of biologics in a given country at the start of our period of observation by creating a weighted

\footnotetext{
32 Surprisingly, additional Somatropin distributors appear to be associated with higher average prices (Table 7), although this result is based off of a very small sample of entrants.

${ }^{33}$ In this case, we see an ambiguous relationship between national pharmaceutical expenditures and prices: in aggregate there is no clear trend, but higher national pharmaceutical expenditures appear to be associated with slightly lower Epoetin prices, but slightly higher Filgrastim prices.
} 
average of reference product prices of three largest biologics that did not have biosimilar entry ${ }^{34}$. This price ratio approximates whether a country was a "high price market" for biologic drugs before biosimilar competition. The instrumental variables regressions result in predictive models of price that are qualitatively and quantitatively similar to those presented in Tables 6 and 7 .

Finally, Table 8 considers penetration of biosimilars as a share of total sales volume. Figure 2a shows that biosimilar volume increases over time, although, as noted above, the theory does not necessarily predict this trend, since competition may cause prices to fall even in the absence of take-up. This is also seen in Table 8 , with, on average, a roughly 5.5 percentage point increase in biosimilar penetration with every passing year. There is a good deal of heterogeneity in this average increase in penetration across drug classes, with biosimilar Epoetin penetration growing at about 9 percentage points per year, biosimilar Filgrastim penetration growing at about 4.1 percentage points per year and biosimilar Somatropin penetration growing at about 2.6 percentage points per year. The penetration of biosimilar Epoetin is higher than for the other two classes of biosimilars in every year by an average of approximately 19 percentage points.

When moving from a setting with no tendering to a tender that guarantees the winner full demand, we observe that stronger tenders are, on average, associated with significantly higher rates of biosimilar penetration on the order of 14.6 percentage points, all else equal. This relationship is mainly driven by Epoetin although the point estimates for the other two drug classes, when modeled separately, are both positive. Finally, the number of non-procurement policies to encourage the use of biosimilars in a country and drug class is associated with higher rates of take-up overall, although these results are not statistically significant.

\footnotetext{
${ }^{34}$ We identify these by looking at the largest biologics markets in all countries over the entire period of observation and taking the top three products, which were Etanercept (brand name Enbrel), Adalimumab (brand name Humira), and Infliximab (brand name Remicade).
} 
One concern about using same-year policy and biosimilar sales data in our regression models is that the full impact of policies may lag their implementation. While we were careful in our data collection and survey wording to focus on only coding a policy as being in place in years in which it had been implemented, we tested for a delay in response to policies by using lagged independent variables. For example, if a country implemented tendering in 2008 and we were worried that we would not see the full impact of the tendering until 2009, we should regress 2009 entry (or price or penetration) on 2008 policies. In robustness tests, we checked all of our regression models for evidence of policy lags and found none; the results of lagged regressions were virtually indistinguishable from the main regressions presented here with respect to both the magnitude and statistical significance of the coefficients estimated.

Another concern may be that omitted variables influence entry decisions of biosimilar firms. Perhaps the most obvious example is a set of political economy questions regarding the existence of a domestic biopharmaceutical industry. For example, do we observe more biosimilar entry in countries with a domestic financial interest in the success of the biosimilar industry? We test for this by defining a binary indicator for "any biosimilar industry" which is equal to one when a firm within a given country is either a licensed manufacturer or marketing authorization holder. Thus, the indicator is positive for countries whose domestic firms stand to gain from biosimilar adoption. We find no clear evidence for the role of domestic industry in predicting adoption, and are therefore less concerned about this potential source of omitted variable bias.

Finally, we undertake a simple counterfactual analysis highlighting the cost savings achieved through biosimilars in Europe, and, perhaps more importantly, the potential cost savings that might be achieved in the presence of strong demand-side institutions. While rough, our back-of-the-envelope estimates suggest that the introduction of biosimilars likely resulted in 
savings of around $\$ 1.5$ billion in 2006 (pre-biosimilar adoption) U.S. dollars through 2014 in our sample of countries and years (Table 9). Looking forward, biosimilar competition has the potential to generate billions of dollars of savings annually in Europe and beyond, if additional drug classes experience biosimilar entry and if current rates of adoption continue.

\section{CONCLUSIONS AND IMPLICATIONS FOR THE UNITED STATES}

We find that entry of both distributors and unique products increases over time and is higher for Epoetin biosimilars than for Filgrastim biosimilars or Somatropin biosimilars. Large markets attract more entrants.

We consider predictors of average product prices following biosimilar competition. Prevailing market prices fall over time at an average rate of about 3.5 percentage points per year following biosimilar entry, and this decline is even steeper in Epoetin and Filgrastim markets. In unreported regressions where the number of entrants is instrumented with national pharmaceutical expenditure, price declines are steeper when there are more biosimilar entrants and when the size of the tender population is larger, (however we do not have enough statistical power in the early data). Quotas for biosimilars seem to raise their prices in some cases, as one might expect if the quota regulation shifts out demand. Aggressive tendering reduces the price for Epoetin, the largest market with the most entry. We see the opposite effect for Somatropin, however, this is a small market with the least competitive activity. Overall, our results on prices are more tentative. We remain concerned that ex post rebates create either measurement error, or even a spurious positive correlation between tendering and high prices. This inability to see an accurate price makes it difficult to identify effects in a small sample. 
We also examine penetration of biosimilars. There is a strong trend for biosimilars as a share of total sales to increase over time with, on average, a roughly 5.5 percentage point increase in biosimilar penetration with every passing year. There is a good deal of heterogeneity in this average increase in penetration, with biosimilar Epoetin penetration growing at about 9 percentage points per year, biosimilar Filgrastim penetration growing at about 4.1 percentage points per year and biosimilar Somatropin penetration growing at about 2.6 percentage points per year. Stronger tenders are, on average, associated with significantly higher rates of biosimilar penetration, and this relationship is mainly driven by Epoetin biosimilars.

Now that the United States has a small amount of biosimilar competition, how should U.S. policymakers structure payer institutions and policies in light of ten years of European experience? First, we assume that policy makers' goals are to create price competition for biologics and lower expenditures. Second, we assume that there will remain many settings in which a physician's prescription is required to switch patients from a reference product to a biosimilar.

In such a setting, procurement incentives will affect prices. If the biosimilar is simply available, the physician will not necessarily have an incentive to learn of its existence or prescribe it - especially if he or she knows the reference product well. Physician administered drugs (PADs) are often dispensed through Medicare part B, which is the part of Medicare that covers drugs administered by a physician during a physician visit. Medicare pays for PADs using a "J-code" that tracks the cost of the drug and reimburses the physician for it. If each version of a biologic has its own J-code, as is the case today, a physician has no incentive to use the biosimilar. If instead the physician were reimbursed for the least costly therapeutic among a set 
of reference and follow-on products, he or she would seek out a low-cost option; and this, in turn, would stimulate manufacturers to compete on price.

Physician-administered drugs are not typically managed by a pharmacy benefits manager, and the medical benefit insurer may not be organizationally enabled to create competition among biosimilars and the reference product. Furthermore, a physician may need to purchase and store expensive biologics in his or her office until they are used by patients. But if those patients are covered by a variety of insurers, each with a different formulary, the physician may not physically be able to inventory all the different versions. Commercial payers who want to run strong formularies will have to work out the logistics of biosimilar distribution. In addition, those payers will have to establish a system that is more precise than J-codes to track which biosimilar product is being administered. ${ }^{35}$

One open policy question is the degree to which biosimilars will be judged to be "substitutable" vs. "interchangeable" in the United States. The strongest tenders (i.e. those for full demand) observed in European countries most represent interchangeability, ${ }^{36}$ whereas other types of tendering more closely mimic the types of settings in which biosimilars are only seen as clinically substitutable. Once a biosimilar is interchangeable, existing U.S. institutions are likely to work well - largely because existing policies are set up for interchangeable small molecules. While it is still too early to know how and when interchangeability will be established and evolve in the U.S. context, draft regulatory guidance on interchangeability was released in early 2017 (FDA, 2017) and FDA policy makers have expressed the expectation that updated or final

\footnotetext{
${ }^{35}$ The Center for Medicare and Medicaid Services (CMS) is considering J codes for provider-administered biosimilars under Medicare Part B and it is expected that private payers would follow suit (Sarpatwari, Avorn, and Kesselheim, 2015)

${ }^{36}$ As defined in the United States as a situation that permits pharmacist substitution.
} 
guidance will be released by $2019 .{ }^{37}$ We find that stronger tenders are, on average, associated with about 14.6 percentage points higher biosimilar penetration (moving from a setting with no tendering to a tender that guarantees the winner full demand), so the issue of exchangeability is likely to have a large impact on U.S. adoption and therefore pharmaceutical expenditure. This will be especially true as additional biosimilar versions of high-cost therapies - including monoclonal antibodies such as Bevacizumab and Trastuzumab, widely used anti-cancer drugs, file for regulatory approval. ${ }^{38}$

In general, the current way we insure, reimburse, and deliver biologic drugs in the United States, makes it difficult for the insurer to bargain for a discount in return for instructing physicians to use a particular version of a biologic drug. Policy makers and commercial insurers in the U.S. will need to analyze their buying institutions and consider new policies and incentives if they would like to realize the full promise of biosimilar treatments.

\footnotetext{
${ }^{37}$ http://raps.org/Regulatory-Focus/News/2017/06/26/27969/FDA-Interchangeable-Biosimilar-Approvals-ExpectedWithin-2-Years/

${ }^{38}$ http://www.gabionline.net/Biosimilars/News/FDA-advisory-committee-to-review-bevacizumab-and-trastuzumabbiosimilars
} 


\section{REFERENCES}

Acemoglu, Daron, and Joshua Linn. "Market Size in Innovation: Theory and Evidence from the Pharmaceutical Industry." Quarterly journal of economics 3 (2004): 1049-1090.

Averch, Harvey, and Leland L. Johnson. "Behavior of the firm under regulatory constraint." The American Economic Review 52.5 (1962): 1052-1069.

Berndt, Ernst R., and Mark R. Trusheim. "Biosimilar and Biobetter Scenarios for the US and Europe: What Should We Expect?." Biobetters. Springer New York, 2015. 315-360.

Berry, Steven T. "Estimation of a Model of Entry in the Airline Industry." Econometrica: Journal of the Econometric Society (1992): 889-917.

Bresnahan, Timothy F., and Peter C. Reiss. "Entry and competition in concentrated markets." Journal of Political Economy (1991): 977-1009.

Bulow, Jeremy. "The gaming of pharmaceutical patents." Innovation policy and the economy 4 (2004): 145-187.

Danzon, Patricia M., and Li-Wei Chao. "Does Regulation Drive Out Competition in Pharmaceutical Markets?*." The Journal of Law and Economics 43, no. 2 (2000): 311358.

DiMasi, Joseph A., and Henry G. Grabowski. "The cost of biopharmaceutical R\&D: is biotech different?." Managerial and Decision Economics28, no. 4-5 (2007): 469-479.

Dubois, Pierre, Olivier de Mouzon, Fiona Scot Morton, and Paul Seabright. "Market size and pharmaceutical innovation." The RAND Journal of Economics 46, no. 4 (2015): 844871.

Duggan, Mark and Fiona Scott Morton. "The Effect of Medicare Part D on Pharmaceutical Prices and Utilization." AER, vol. 100, no. 1, 2010. 590-607.

FDA. "Scientific Considerations in Demonstrating Biosimilariy to a Reference Product: Guidance for Industry". Food and Drug Administration. April, 2015.

FDA. "Considerations in Demonstrating Interchangeability With a Reference Product; Draft Guidance". Food and Drug Administration. January, 2017.

FTC. "In Response to a Request for Comments on Its Guidance for Industry on the "Nonproprietary Naming of Biological Products; Draft Guidance for Industry; Availability"." [Docket No. FDA-2013-D-1543]2. 80 Fed. Reg. 52296. Submitted on October 27, 2015

Ganslandt, Mattias, and Keith E. Maskus. "Parallel imports and the pricing of pharmaceutical products: evidence from the European Union." Journal of health economics 23, no. 5 (2004): 1035-1057. 
Grabowski, Henry G., David B. Ridley, and Kevin A. Schulman. "Entry and competition in generic biologics." Managerial and Decision Economics28, no. 4-5 (2007): 439-451.

Grabowski, Henry, Iain Cockburn, and Genia Long. "The market for follow-on biologics: how will it evolve?." Health Affairs 25.5 (2006): 1291-1301.

Grabowski, Henry, and John Vernon. "Longer patents for lower imitation barriers: The 1984 Drug Act." The American Economic Review 76, no. 2 (1986): 195-198.

Grabowski, Henry. "Follow-on biologics: data exclusivity and the balance between innovation and competition." Nature Reviews Drug Discovery7.6 (2008): 479-488.

Hamburg, Margaret A. "Celebrating 30 years of easier access to cost-saving generic drugs." Posted on September 24, 2014 by FDA Voice

$<$ http://blogs.fda.gov/fdavoice/index.php/2014/09/celebrating-30-years-of-easier-accessto-cost-saving-generic-drugs $>$.

IMS Institute for Healthcare Informatics. (2016). Medicines Use and Spending in the U.S. - A Review of 2015 and Outlook to 2020.

Inderst, Roman, and Tommaso Valletti. "Price discrimination in input markets." The RAND Journal of Economics 40, no. 1 (2009): 1-19.

Kozlowski, Steven, Janet Woodcock, Karen Midthun, and Rachel Behrman Sherman. "Developing the nation's biosimilars program." New England Journal of Medicine 365, no. 5 (2011): 385-388.

Kyle, Margaret K. "Pharmaceutical price controls and entry strategies." The Review of Economics and Statistics 89, no. 1 (2007): 88-99.

Laffont, Jean-Jacques, and Jean Tirole. A theory of incentives in procurement and regulation. MIT press, 1993.

MacNeil, J.S. and Douglas, F., 2007. Challenges to Establishing a Regulatory Framework for Approving Follow-on Biologics: A Background Paper. DRAFT Manuscript, MIT Center for Biological Innovation.

Manheim, Bruce S., Patricia Granahan, and Kenneth J. Dow. "'Follow-On Biologics': Ensuring Continued Innovation In The Biotechnology Industry." Health Affairs 25.2 (2006): 394-404.

PhRMA. (Fall 2015). "Biosimilars Naming: Why Terminology Matters and Where It Stands."

Reiffen, David, and Michael R. Ward. "Generic drug industry dynamics." The Review of Economics and Statistics 87, no. 1 (2005): 37-49.

Rovira, J., et. al. The impact of biosimilars' entry in the EU market. Granada (Spain): Andalusian School of Public Health, 2011. 
Sarpatwari, Ameet, Jerry Avorn, and Aaron S. Kesselheim. "Progress and hurdles for follow-on biologics." New England Journal of Medicine 372.25 (2015): 2380-2382.

Scott Morton, Fiona M. "Entry decisions in the generic pharmaceutical industry." The Rand journal of economics (1999): 421-440.

Scott Morton, Fiona M. "Barriers to entry, brand advertising, and generic entry in the US pharmaceutical industry." International Journal of Industrial Organization 18, no. 7 (2000): 1085-1104. 
Figures and Tables:

Figure 1: Biosimilar share of total unit sales (2014 or most recent year)

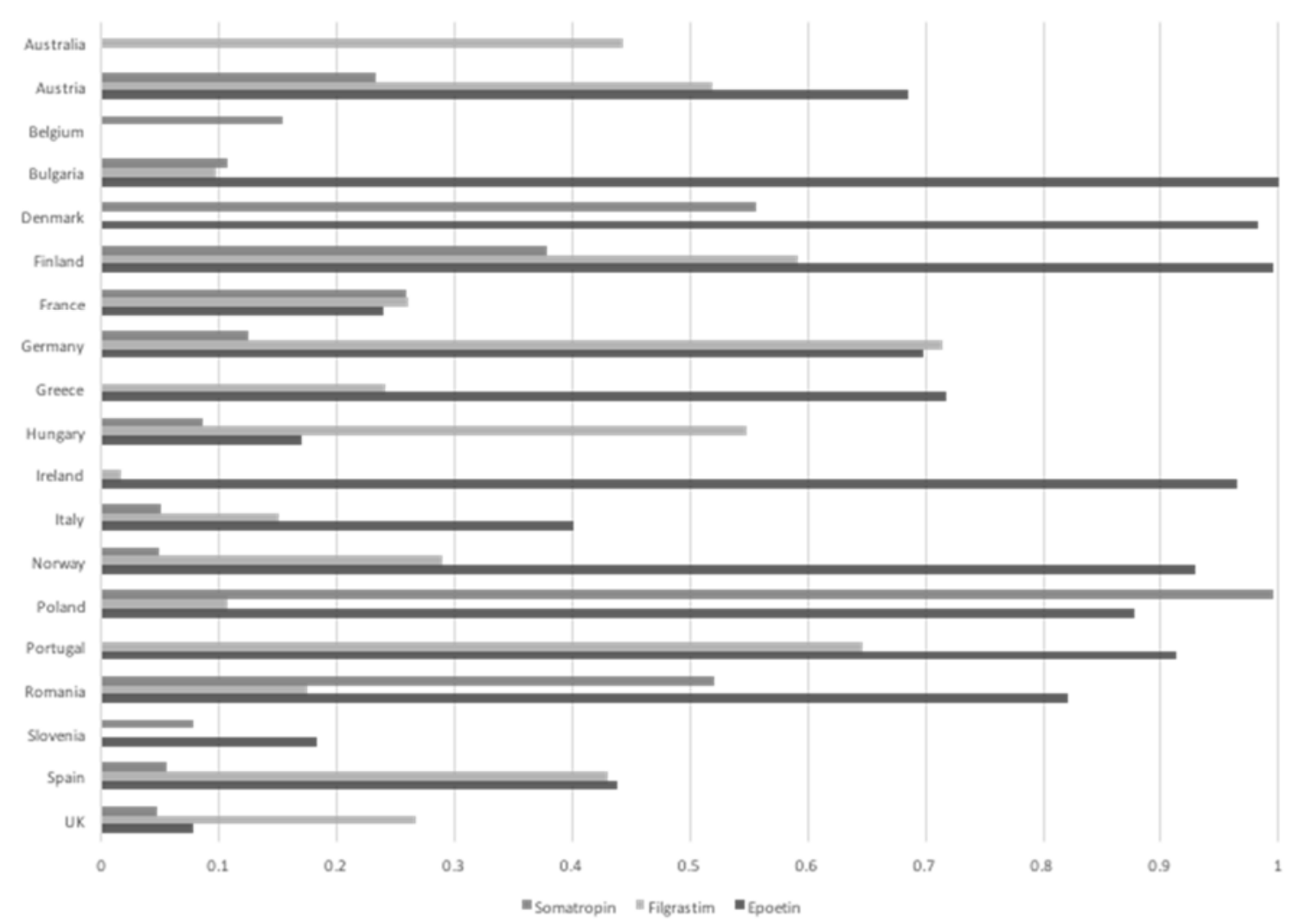


Figure 2: Aggregate growth of biosimilars

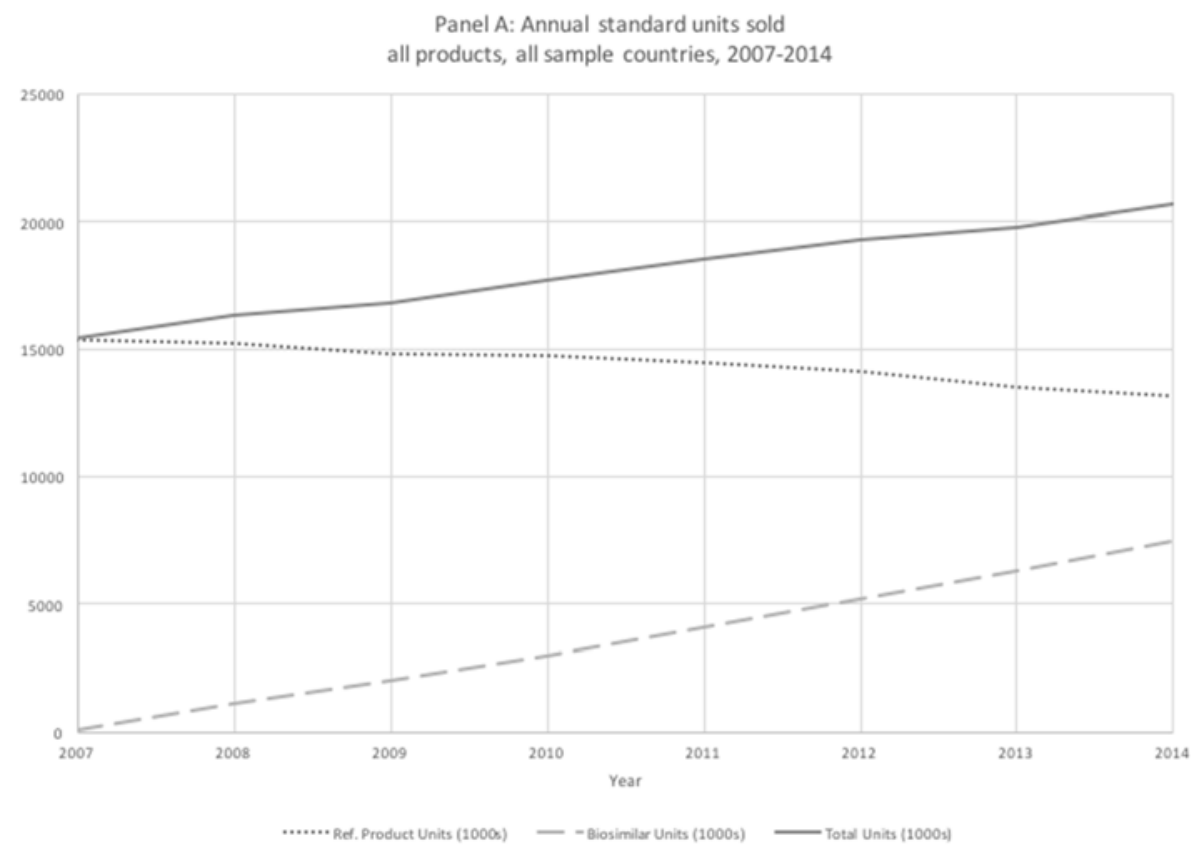

Panel B: Annual spending (2006 U.S. Dollars) all products, all sample countries, 2007-2014

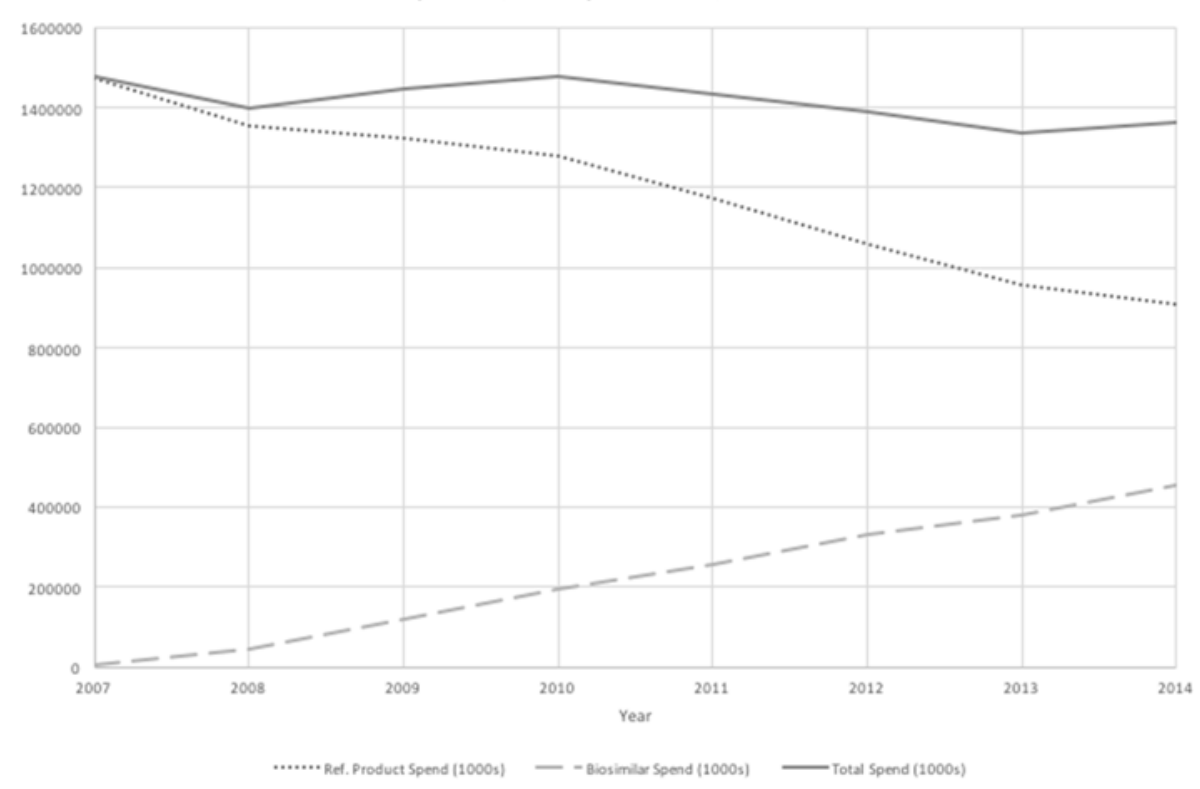


Figure 3: Entrants and distributors over time
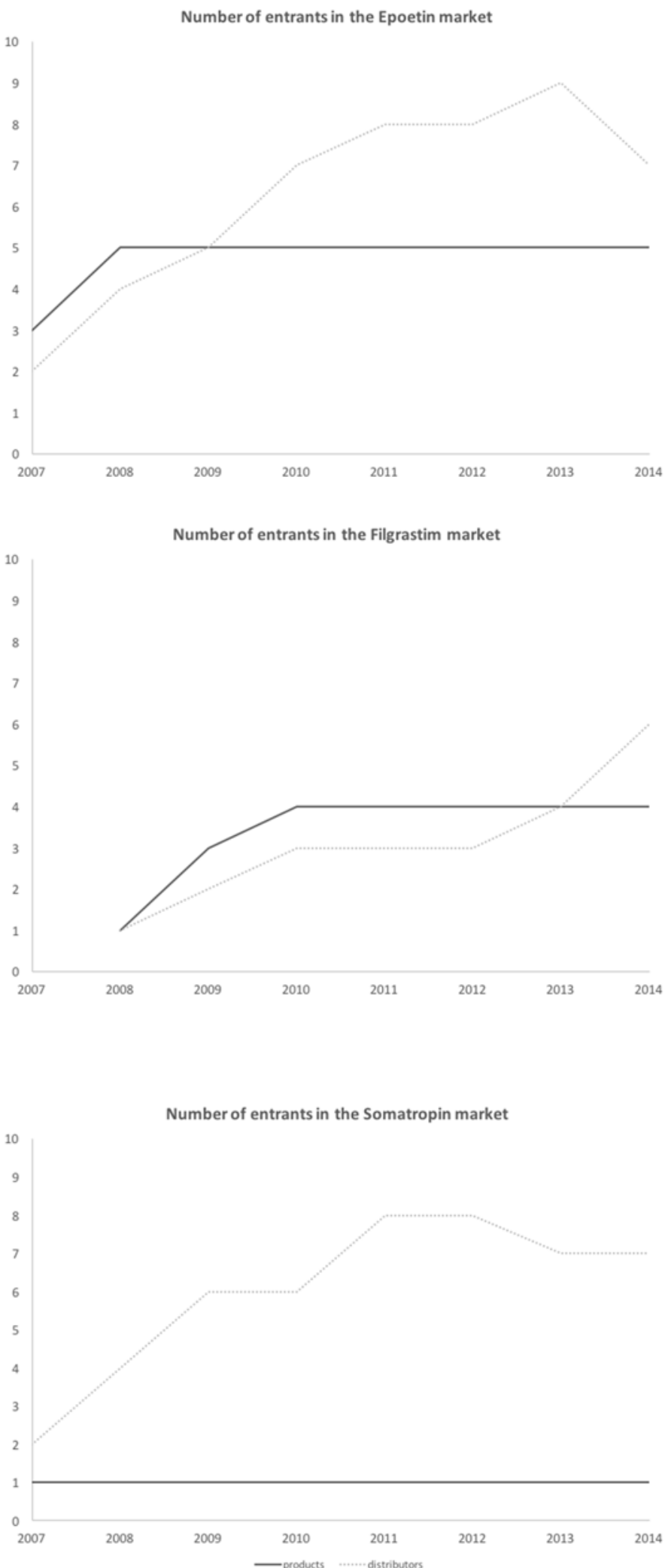
Table 1: List of biosimilars in sample by EMA approval date

\begin{tabular}{|c|c|c|c|c|c|}
\hline Active Substance & $\begin{array}{l}\text { International Product } \\
\text { Name }\end{array}$ & Indication(s) & $\begin{array}{l}\text { EMA Approval } \\
\text { Month / Year }\end{array}$ & $\begin{array}{l}\text { Number of countries } \\
\text { with any entry }\end{array}$ & $\begin{array}{l}\text { Number of } \\
\text { distributors in sample }\end{array}$ \\
\hline Somatropin & Omnitrope & Dwarfism, Pituitary; Prader-Willi Syndrome; Turner Syndrome & $04 / 2006$ & 19 & 11 \\
\hline Somatropin & Valtropin & Dwarfism, Pituitary; Turner Syndrome & $04 / 2006$ & & \\
\hline Epoetin Alfa & Binocrit & Anemia; Kidney Failure, Chronic & $08 / 2007$ & 19 & 4 \\
\hline Epoetin Alfa & Abseamed & Anemia; Cancer; Kidney Failure, Chronic & $08 / 2007$ & 6 & 6 \\
\hline Epoetin Alfa & Epoetin Alfa Hexal & Anemia; Cancer; Kidney Failure, Chronic & $08 / 2007$ & 1 & 1 \\
\hline Epoetin Zeta & Silapo & Anemia; Blood Transfusion, Autologous; Cancer; Kidney Failure, Chronic & $12 / 2007$ & 1 & 1 \\
\hline Epoetin Zeta & Retacrit & Anemia; Blood Transfusion, Autologous; Cancer, Kidney Failure, Chronic & $12 / 2007$ & 19 & 2 \\
\hline Filgrastim & Tevagrastim & Cancer; Hematopoietic Stem Cell Transplantation; Neutropenia & $09 / 2008$ & 2 & 2 \\
\hline Filgrastim & Filgrastim Ratiopharm & Cancer; Hematopoietic Stem Cell Transplantation; Neutropenia & $09 / 2008$ & & \\
\hline Filgrastim & Ratiograstim & Cancer; Hematopoietic Stem Cell Transplantation; Neutropenia & $09 / 2008$ & 13 & 1 \\
\hline Filgrastim & Biograstim & Cancer; Hematopoietic Stem Cell Transplantation; Neutropenia & $09 / 2008$ & - & - \\
\hline Filgrastim & Zarzio & Cancer; Hematopoietic Stem Cell Transplantation; Neutropenia & $02 / 2009$ & 2 & 1 \\
\hline Filgrastim & Filgrastim Hexal & Cancer; Hematopoietic Stem Cell Transplantation; Neutropenia & $06 / 2009$ & - & - \\
\hline Filgrastim & Nivestim & Cancer; Hematopoietic Stem Cell Transplantation; Neutropenia & $08 / 2010$ & 19 & 3 \\
\hline
\end{tabular}

Source: http://www.ema.europa.eu, MIDAS, authors' own analysis 
Table 2: Biosimilar sales by class and year in 2006 U.S. Dollars, all sample countries

\begin{tabular}{|c|c|c|}
\hline & \multicolumn{2}{|c|}{ Epoetin } \\
\hline & Total & Biosimilar \\
\hline 2007 & 731,241 & 1,498 \\
\hline 2008 & 664,266 & 31,114 \\
\hline 2009 & 671,955 & 65,319 \\
\hline 2010 & 666,872 & 95,000 \\
\hline 2011 & 640,325 & 129,940 \\
\hline 2012 & 619,700 & 158,407 \\
\hline 2013 & 614,329 & 189,529 \\
\hline 2014 & 623,509 & 231,793 \\
\hline
\end{tabular}

\begin{tabular}{|c|c|}
\hline \multicolumn{2}{|c|}{ Filgrastim } \\
\hline Total & Biosimilar \\
\hline 323,563 & \\
\hline 301,305 & 451.4976 \\
\hline 307,202 & 28,998 \\
\hline 324,663 & 56,542 \\
\hline 329,584 & 66,193 \\
\hline 329,687 & 80,222 \\
\hline 328,663 & 91,773 \\
\hline 350,407 & 109,689 \\
\hline
\end{tabular}

\begin{tabular}{|c|c|}
\hline \multicolumn{2}{|c|}{ Somatropin } \\
\hline Total & Biosimilar \\
\hline 424,140 & 4,030 \\
\hline 433,877 & 13,737 \\
\hline 465,462 & 25,982 \\
\hline 485,439 & 44,491 \\
\hline 461,851 & 61,957 \\
\hline 439,741 & 93,514 \\
\hline 393,782 & 98,515 \\
\hline 387,801 & 112,556 \\
\hline
\end{tabular}

\section{Table 3: Biosimilar market and procurement details (averages across all years)}

\begin{tabular}{lrrr} 
& Epoetin & Filgrastim Somatropi \\
\hline IMS Data & & & \\
Average number of distributors per country year & 1.41 & 0.99 & 0.84 \\
Average number of products per country year & 2.02 & 1.59 & 1 \\
Average relative price: biosimilar (current) vs. reference product (base year) & 0.93 & 0.61 & 1.38 \\
Average mid 90\% relative price: biosim (current) vs. ref product (base year) & 0.86 & 0.65 & 1.12 \\
Average relative price: average (current) vs. reference product (base year) & 0.96 & 0.81 & 0.98 \\
Average fraction of biosimilar sales & 0.29 & 0.13 & 0.09 \\
\hline Tenders & & & \\
Average size of tender population (millions) & 1.09 & 1.09 & 2.84 \\
Country-years with tendering & 0.94 & 0.93 & 0.87 \\
Country-years for which winner of unit tender gets new patients & 0.71 & 0.7 & 0.65 \\
Country-years for which winner of unit tender gets all demand & 0.59 & 0.59 & 0.53 \\
Average tender strength (0 [none] - 1 [winner takes all]) & 0.75 & 0.75 & 0.69 \\
Interaction of tender strength * tender size (millions) & 0.12 & 0.12 & 0.16 \\
\hline Other incentive and policies & & & \\
Country-years with non-financial physician pressure to use biosimilar & 0.46 & 0.46 & 0.46 \\
Country-years with physician financial incentive(s) to use biosimilar & 0.3 & 0.3 & 0.3 \\
Country-years with any physician education about biosimilars & 0.27 & 0.28 & 0.27 \\
Country-years with any public/patient education & 0.12 & 0.13 & 0.12 \\
Country-years with any domestic biosimilar effectiveness study & 0.16 & 0.19 & 0.16 \\
Country-years with any biosimilar quota & 0.14 & 0.09 & 0.09 \\
Average number of non-procurement incentives to use biosimilars & 1.3 & 1.35 & 1.3 \\
\hline & & & \\
Market Size Indicators & & & \\
GDP (2010 USD\$), trillions & & & $1.70 \%$ \\
Average pharmaceutical expenditure as a \% of GDP & & 12.49 \\
National pharma expenditure (billions) & & & \\
\hline
\end{tabular}


Table 4: Unit price as a \% of Median sample price for reference products, 2007 *

\begin{tabular}{lrrr} 
country & Epoetin & Filgrastim & Somatropin \\
\hline Australia & 212.9 & 136.3 & 100.0 \\
Austria & 50.6 & 130.1 & 114.3 \\
Belgium & 211.9 & 112.3 & 126.7 \\
Bulgaria & 25.0 & 99.3 & 50.6 \\
Denmark & 275.2 & 115.5 & 140.5 \\
Finland & 210.1 & 93.6 & 154.3 \\
France & 151.7 & 142.2 & 198.7 \\
Germany & 100.0 & 154.1 & 207.1 \\
Greece & 144.0 & 95.2 & 140.0 \\
Hungary & 51.7 & 78.1 & 116.7 \\
Ireland & 290.1 & 114.8 & 62.2 \\
Italy & 168.7 & 89.0 & 52.4 \\
Latvia & 73.3 & 157.7 & 83.6 \\
Lithuania & 34.7 & 63.4 & 87.6 \\
Norway & 94.0 & 100.0 & 71.7 \\
Poland & 19.9 & 66.4 & 31.6 \\
Portugal & 24.6 & 82.5 & 109.8 \\
Romania & 60.5 & 66.6 & 49.9 \\
Slovakia & 190.3 & 172.4 & 136.3 \\
Slovenia & 37.4 & 132.0 & 138.9 \\
Spain & 190.6 & 69.8 & 91.9 \\
Sweden & 72.0 & 108.9 & 88.3 \\
UK & 192.9 & 55.2 & 80.4 \\
\hline
\end{tabular}

*with the exception of Portugal (base year $=2009$ for Epoetin and 2010 for Filgrastim) and Greece (base year $=2008$ for Somatropin) 
Table 5: Entry of products and distributors: marginal effects from Poisson models

\begin{tabular}{|c|c|c|c|c|c|c|c|c|}
\hline & \multicolumn{4}{|c|}{ Outcome $=$ \# of distributors at country-year-biosimilar level } & \multicolumn{4}{|c|}{ Outcome $=\#$ of products at country-year-biosimilar level } \\
\hline & Full Sample & Epoetin & Filgrastim & Somatropin & Full Sample & Epoetin & Filgrastim & Somatropin \\
\hline Years since biosimilar approval & $\begin{array}{c}0.176^{* *} \\
(0.020)\end{array}$ & $\begin{array}{c}0.192 * * \\
(0.027)\end{array}$ & $\begin{array}{c}0.226 * * \\
(0.030)\end{array}$ & $\begin{array}{c}0.108^{* *} \\
(0.025)\end{array}$ & $\begin{array}{c}0.028^{* *} \\
(0.008)\end{array}$ & $\begin{array}{c}0.025 \\
(0.019)\end{array}$ & $\begin{array}{c}0.076^{* *} \\
(0.017)\end{array}$ & $\begin{array}{c}0.000 \\
(0.000)\end{array}$ \\
\hline Epoetin & $\begin{array}{c}0.486^{* *} \\
(0.180)\end{array}$ & & & & $\begin{array}{c}0.712 * * \\
(0.092)\end{array}$ & & & \\
\hline Filgrastim & $\begin{array}{c}0.239 \\
(0.214)\end{array}$ & & & & $\begin{array}{c}0.494 * * \\
(0.088)\end{array}$ & & & \\
\hline National pharma expenditure (billions) & $\begin{array}{c}0.026^{* *} \\
(0.007)\end{array}$ & $\begin{array}{c}0.022 * * \\
(0.007)\end{array}$ & $\begin{array}{c}0.022 * * \\
(0.005)\end{array}$ & $\begin{array}{c}0.037^{* *} \\
(0.009)\end{array}$ & $\begin{array}{c}0.009^{* *} \\
(0.003)\end{array}$ & $\begin{array}{l}0.012^{*} \\
(0.005)\end{array}$ & $\begin{array}{c}0.012^{* *} \\
(0.003)\end{array}$ & $\begin{array}{c}0.000 \\
(0.000)\end{array}$ \\
\hline Any biosimilar quota & $\begin{array}{c}0.135 \\
(0.195)\end{array}$ & $\begin{array}{c}0.307 \\
(0.276)\end{array}$ & $\begin{array}{c}0.012 \\
(0.177)\end{array}$ & $\begin{array}{c}0.062 \\
(0.438)\end{array}$ & $\begin{array}{c}0.169 \\
(0.173)\end{array}$ & $\begin{array}{c}0.189 \\
(0.222)\end{array}$ & $\begin{array}{c}-0.063 \\
(0.147)\end{array}$ & $\begin{array}{c}0.000 \\
(0.000)\end{array}$ \\
\hline Tender size (fraction of population) & $\begin{array}{l}-0.142 \\
(0.227)\end{array}$ & $\begin{array}{l}-0.330 \\
(0.316)\end{array}$ & $\begin{array}{c}0.089 \\
(0.321)\end{array}$ & $\begin{array}{c}0.060 \\
(0.369)\end{array}$ & $\begin{array}{l}-0.055 \\
(0.106)\end{array}$ & $\begin{array}{l}-0.213 \\
(0.191)\end{array}$ & $\begin{array}{l}0.175+ \\
(0.101)\end{array}$ & $\begin{array}{c}0.000 \\
(0.000)\end{array}$ \\
\hline Strength of tender ( 0 [none] - 1 [winner takes all] $)$ & $\begin{array}{c}0.331 \\
(0.240)\end{array}$ & $\begin{array}{c}0.564 \\
(0.438)\end{array}$ & $\begin{array}{c}0.149 \\
(0.349)\end{array}$ & $\begin{array}{l}-0.118 \\
(0.445)\end{array}$ & $\begin{array}{l}-0.064 \\
(0.105)\end{array}$ & $\begin{array}{c}0.087 \\
(0.182)\end{array}$ & $\begin{array}{l}-0.148 \\
(0.262)\end{array}$ & $\begin{array}{c}0.000 \\
(0.000)\end{array}$ \\
\hline Number of non-procurement incentives to use biosimilars & $\begin{array}{c}0.033 \\
(0.077)\end{array}$ & $\begin{array}{c}0.018 \\
(0.109)\end{array}$ & $\begin{array}{c}0.033 \\
(0.073)\end{array}$ & $\begin{array}{c}0.064 \\
(0.081)\end{array}$ & $\begin{array}{c}0.006 \\
(0.053)\end{array}$ & $\begin{array}{c}0.014 \\
(0.089)\end{array}$ & $\begin{array}{l}-0.014 \\
(0.038)\end{array}$ & $\begin{array}{c}0.000 \\
(0.000)\end{array}$ \\
\hline $\begin{array}{l}\text { Observations } \\
\text { R-squared }\end{array}$ & $\begin{array}{c}499 \\
0.489\end{array}$ & $\begin{array}{c}174 \\
0.538\end{array}$ & $\begin{array}{c}151 \\
0.466\end{array}$ & $\begin{array}{c}174 \\
0.575\end{array}$ & $\begin{array}{c}320 \\
0.505\end{array}$ & $\begin{array}{c}117 \\
0.452\end{array}$ & $\begin{array}{c}96 \\
0.333\end{array}$ & $\begin{array}{l}107 \\
\mathrm{n} / \mathrm{a}\end{array}$ \\
\hline
\end{tabular}

Standard errors in parentheses, clustered at the country level

$* * \mathrm{p}<0.01, * \mathrm{p}<0.05,+\mathrm{p}<0.1$ 
Table 6: Relative prices: current biosimilar price vs. base-year reference product price

\begin{tabular}{|c|c|c|c|c|c|c|c|c|}
\hline & \multicolumn{8}{|c|}{ Outcome $=$ [current price of biosim. $/$ base year price of ref. product $]$ at country-year-biosimilar level } \\
\hline Years since biosimilar approval & $\begin{array}{c}\text { Full Sample } \\
-0.034 \\
(0.024)\end{array}$ & $\begin{array}{c}\text { Epoetin } \\
-0.077+ \\
(0.040)\end{array}$ & $\begin{array}{c}\text { Filgrastim } \\
-0.055^{* *} \\
(0.012)\end{array}$ & $\begin{array}{c}\text { Somatropin } \\
0.027 \\
(0.030)\end{array}$ & Full Sample & Epoetin & Filgrastim & Somatropin \\
\hline Number of distributors at country yr class level & & & & & $\begin{array}{l}-0.017 \\
(0.035)\end{array}$ & $\begin{array}{l}-0.038 \\
(0.051)\end{array}$ & $\begin{array}{l}-0.022 \\
(0.041)\end{array}$ & $\begin{array}{c}0.043 \\
(0.096)\end{array}$ \\
\hline Epoetin & $\begin{array}{c}-0.258 \\
(0.211)\end{array}$ & & & & $\begin{array}{c}-0.251 \\
(0.203)\end{array}$ & & & \\
\hline Filgrastim & $\begin{array}{c}-0.456^{* *} \\
(0.149)\end{array}$ & & & & $\begin{array}{c}-0.439 * * \\
(0.147)\end{array}$ & & & \\
\hline National pharma expenditure (billions) & $\begin{array}{c}0.000 \\
(0.002)\end{array}$ & $\begin{array}{c}-0.016^{*} \\
(0.006)\end{array}$ & $\begin{array}{c}0.004^{* *} \\
(0.001)\end{array}$ & $\begin{array}{c}0.009 \\
(0.007)\end{array}$ & $\begin{array}{c}0.001 \\
(0.003)\end{array}$ & $\begin{array}{l}-0.015^{*} \\
(0.006)\end{array}$ & $\begin{array}{l}0.005^{*} \\
(0.002)\end{array}$ & $\begin{array}{c}0.006 \\
(0.010)\end{array}$ \\
\hline Any biosimilar quota & $\begin{array}{c}0.258 \\
(0.207)\end{array}$ & $\begin{array}{l}0.462+ \\
(0.238)\end{array}$ & $\begin{array}{l}0.247 * \\
(0.092)\end{array}$ & $\begin{array}{c}0.488 \\
(0.354)\end{array}$ & $\begin{array}{c}0.238 \\
(0.205)\end{array}$ & $\begin{array}{l}0.478^{*} \\
(0.214)\end{array}$ & $\begin{array}{c}0.167 \\
(0.108)\end{array}$ & $\begin{array}{c}0.518 \\
(0.358)\end{array}$ \\
\hline Tender size (fraction of population) & $\begin{array}{c}0.062 \\
(0.132)\end{array}$ & $\begin{array}{c}0.002 \\
(0.234)\end{array}$ & $\begin{array}{c}0.017 \\
(0.051)\end{array}$ & $\begin{array}{c}0.109 \\
(0.569)\end{array}$ & $\begin{array}{c}0.069 \\
(0.125)\end{array}$ & $\begin{array}{c}-0.015 \\
(0.259)\end{array}$ & $\begin{array}{c}0.077 \\
(0.063)\end{array}$ & $\begin{array}{c}0.105 \\
(0.585)\end{array}$ \\
\hline Strength of tender ( 0 [none] - 1 [winner takes all] $)$ & $\begin{array}{l}-0.134 \\
(0.202)\end{array}$ & $\begin{array}{c}-0.711 * * \\
(0.217)\end{array}$ & $\begin{array}{c}0.086 \\
(0.114)\end{array}$ & $\begin{array}{l}-0.170 \\
(0.461)\end{array}$ & $\begin{array}{c}-0.142 \\
(0.203)\end{array}$ & $\begin{array}{c}-0.744 * * \\
(0.231)\end{array}$ & $\begin{array}{c}0.089 \\
(0.139)\end{array}$ & $\begin{array}{c}-0.165 \\
(0.461)\end{array}$ \\
\hline Number of non-procurement incentives to use biosimilars & $\begin{array}{l}-0.019 \\
(0.033)\end{array}$ & $\begin{array}{c}0.011 \\
(0.071)\end{array}$ & $\begin{array}{c}-0.079 * \\
(0.029)\end{array}$ & $\begin{array}{c}-0.012 \\
(0.160)\end{array}$ & $\begin{array}{c}-0.023 \\
(0.033)\end{array}$ & $\begin{array}{c}0.004 \\
(0.072)\end{array}$ & $\begin{array}{c}-0.083 * \\
(0.032)\end{array}$ & $\begin{array}{l}-0.005 \\
(0.164)\end{array}$ \\
\hline Observations & 278 & 103 & 87 & 88 & 278 & 103 & 87 & 88 \\
\hline R-squared & 0.162 & 0.275 & 0.474 & 0.132 & 0.149 & 0.220 & 0.311 & 0.130 \\
\hline
\end{tabular}


Table 7: Relative prices: current average market price (all biologics) vs. base-year reference product price

\begin{tabular}{|c|c|c|c|c|c|c|c|c|}
\hline & \multicolumn{8}{|c|}{ Outcome $=$ [current average market price $/$ base year price of ref. product] at country-year-biosimilar level } \\
\hline Years since biosimilar approval & $\begin{array}{c}\text { Full Sample } \\
-0.035^{* *} \\
(0.009)\end{array}$ & $\begin{array}{c}\text { Epoetin } \\
-0.037 * * \\
(0.012)\end{array}$ & $\begin{array}{c}\text { Filgrastim } \\
-0.078 * * \\
(0.011)\end{array}$ & $\begin{array}{c}\text { Somatropin } \\
-0.011 \\
(0.015)\end{array}$ & Full Sample & Epoetin & Filgrastim & Somatropin \\
\hline Number of distributors at country yr class level & & & & & $\begin{array}{c}-0.024 * \\
(0.010)\end{array}$ & $\begin{array}{c}-0.066 * * \\
(0.022)\end{array}$ & $\begin{array}{c}-0.072 * \\
(0.030)\end{array}$ & $\begin{array}{c}0.052^{* *} \\
(0.016)\end{array}$ \\
\hline Epoetin & $\begin{array}{c}-0.082 \\
(0.072)\end{array}$ & & & & $\begin{array}{l}-0.068 \\
(0.069)\end{array}$ & & & \\
\hline Filgrastim & $\begin{array}{c}-0.111+ \\
(0.060)\end{array}$ & & & & $\begin{array}{l}-0.091 \\
(0.063)\end{array}$ & & & \\
\hline National pharma expenditure (billions) & $\begin{array}{c}-0.000 \\
(0.001)\end{array}$ & $\begin{array}{c}-0.004 \\
(0.004)\end{array}$ & $\begin{array}{c}0.003 * * \\
(0.001)\end{array}$ & $\begin{array}{c}0.001 \\
(0.002)\end{array}$ & $\begin{array}{c}0.001 \\
(0.001)\end{array}$ & $\begin{array}{l}-0.001 \\
(0.003)\end{array}$ & $\begin{array}{c}0.005^{* *} \\
(0.001)\end{array}$ & $\begin{array}{c}-0.001 \\
(0.002)\end{array}$ \\
\hline Any biosimilar quota & $\begin{array}{c}0.139 \\
(0.121)\end{array}$ & $\begin{array}{c}0.080 \\
(0.155)\end{array}$ & $\begin{array}{l}0.135+ \\
(0.068)\end{array}$ & $\begin{array}{c}0.318^{* *} \\
(0.099)\end{array}$ & $\begin{array}{c}0.115 \\
(0.114)\end{array}$ & $\begin{array}{c}0.133 \\
(0.090)\end{array}$ & $\begin{array}{c}0.027 \\
(0.077)\end{array}$ & $\begin{array}{c}0.315^{* *} \\
(0.089)\end{array}$ \\
\hline Tender size (fraction of population) & $\begin{array}{c}0.045 \\
(0.069)\end{array}$ & $\begin{array}{l}-0.001 \\
(0.123)\end{array}$ & $\begin{array}{c}0.063 \\
(0.037)\end{array}$ & $\begin{array}{c}0.004 \\
(0.080)\end{array}$ & $\begin{array}{c}0.048 \\
(0.069)\end{array}$ & $\begin{array}{l}-0.047 \\
(0.110)\end{array}$ & $\begin{array}{l}0.146^{*} \\
(0.053)\end{array}$ & $\begin{array}{l}-0.007 \\
(0.071)\end{array}$ \\
\hline Strength of tender $(0$ [none] - 1 [winner takes all] $)$ & $\begin{array}{c}0.083 \\
(0.069)\end{array}$ & $\begin{array}{l}-0.112 \\
(0.151)\end{array}$ & $\begin{array}{c}0.038 \\
(0.086)\end{array}$ & $\begin{array}{l}0.187 * \\
(0.087)\end{array}$ & $\begin{array}{c}0.077 \\
(0.078)\end{array}$ & $\begin{array}{l}-0.089 \\
(0.147)\end{array}$ & $\begin{array}{c}0.029 \\
(0.128)\end{array}$ & $\begin{array}{l}0.194 * \\
(0.081)\end{array}$ \\
\hline Number of non-procurement incentives to use biosimilars & $\begin{array}{l}-0.027 \\
(0.020)\end{array}$ & $\begin{array}{c}0.001 \\
(0.038)\end{array}$ & $\begin{array}{c}-0.063 * * \\
(0.018)\end{array}$ & $\begin{array}{c}-0.014 \\
(0.026)\end{array}$ & $\begin{array}{l}-0.031 \\
(0.022)\end{array}$ & $\begin{array}{c}0.001 \\
(0.039)\end{array}$ & $\begin{array}{c}-0.076^{* *} \\
(0.024)\end{array}$ & $\begin{array}{c}-0.022 \\
(0.025)\end{array}$ \\
\hline Observations & 282 & 95 & 88 & 99 & 282 & 95 & 88 & 99 \\
\hline R-squared & 0.168 & 0.135 & 0.633 & 0.294 & 0.099 & 0.134 & 0.307 & 0.340 \\
\hline
\end{tabular}


Table 8: Biosimilar share of total sales (2006 Dollars)

\begin{tabular}{|c|c|c|c|c|}
\hline & \multicolumn{4}{|c|}{ Outcome $=$ biosimilar share of total sales } \\
\hline Years since biosimilar approval & $\begin{array}{c}\text { Full Sample } \\
0.055^{* *} \\
(0.007)\end{array}$ & $\begin{array}{l}\text { Epoetin } \\
0.090^{* *} \\
(0.014)\end{array}$ & $\begin{array}{c}\text { Filgrastim } \\
0.041 * * \\
(0.009)\end{array}$ & $\begin{array}{c}\text { Somatropin } \\
0.026^{* *} \\
(0.008)\end{array}$ \\
\hline Epoetin & $\begin{array}{c}0.189 * * \\
(0.038)\end{array}$ & & & \\
\hline Filgrastim & $\begin{array}{c}0.076+ \\
(0.044)\end{array}$ & & & \\
\hline National pharma expenditure (billions) & $\begin{array}{c}0.001 \\
(0.001)\end{array}$ & $\begin{array}{c}-0.000 \\
(0.003)\end{array}$ & $\begin{array}{c}0.003 \\
(0.002)\end{array}$ & $\begin{array}{c}0.000 \\
(0.001)\end{array}$ \\
\hline Any biosimilar quota & $\begin{array}{c}0.017 \\
(0.056)\end{array}$ & $\begin{array}{c}0.040 \\
(0.092)\end{array}$ & $\begin{array}{l}-0.021 \\
(0.077)\end{array}$ & $\begin{array}{c}0.052 \\
(0.110)\end{array}$ \\
\hline Tender size (fraction of population) & $\begin{array}{c}0.028 \\
(0.068)\end{array}$ & $\begin{array}{c}-0.069 \\
(0.066)\end{array}$ & $\begin{array}{l}-0.010 \\
(0.070)\end{array}$ & $\begin{array}{c}0.160 \\
(0.135)\end{array}$ \\
\hline Strength of tender ( 0 [none] - 1 [winner takes all] $)$ & $\begin{array}{c}0.146^{* *} \\
(0.044)\end{array}$ & $\begin{array}{l}0.303^{*} \\
(0.119)\end{array}$ & $\begin{array}{c}0.058 \\
(0.066)\end{array}$ & $\begin{array}{c}0.045 \\
(0.061)\end{array}$ \\
\hline Number of non-procurement incentives to use biosimilars & $\begin{array}{c}0.011 \\
(0.013)\end{array}$ & $\begin{array}{c}0.008 \\
(0.021)\end{array}$ & $\begin{array}{c}0.028 \\
(0.026)\end{array}$ & $\begin{array}{c}0.004 \\
(0.018)\end{array}$ \\
\hline Observations & 499 & 174 & 151 & 174 \\
\hline R-squared & 0.370 & 0.486 & 0.328 & 0.262 \\
\hline
\end{tabular}

Standard errors in parentheses, clustered at the country level. OLS models.

$* * \mathrm{p}<0.01, * \mathrm{p}<0.05,+\mathrm{p}<0.1$ 
Table 9: Estimated savings from biosimilars

\begin{tabular}{|c|c|c|c|c|c|c|c|c|c|}
\hline \multirow[b]{2}{*}{ Country } & \multicolumn{3}{|c|}{$\begin{array}{l}\text { Total estimated savings } \\
\text { (millions of 2006 Dollars) }\end{array}$} & \multicolumn{3}{|c|}{$\begin{array}{l}\text { Maximum annual savings } \\
\text { (millions of } 2006 \text { Dollars) }\end{array}$} & \multicolumn{3}{|c|}{$\begin{array}{c}\text { Maximum annual savings per standard unit } \\
\text { (2006 Dollars) }\end{array}$} \\
\hline & Epoetin & Filgrastim & Somatropin & Epoetin & Filgrastim & Somatropin & Epoetin & Filgrastim & Somatropin \\
\hline Australia & -37.94 & 41.59 & 9.33 & 1.65 & 9.78 & 6.61 & 6.12 & 71.70 & 54.55 \\
\hline Austria & -4.07 & 21.01 & 2.39 & 1.31 & 2.89 & 0.83 & 18.38 & 56.51 & 61.62 \\
\hline Belgium & 16.75 & 8.41 & 9.95 & 4.98 & 2.64 & 2.67 & 30.49 & 49.04 & 55.18 \\
\hline Bulgaria & 14.82 & 4.42 & -1.73 & 5.45 & 1.24 & 0.13 & 21.31 & 127.83 & 11.29 \\
\hline Denmark & -0.23 & 1.83 & 8.79 & 0.34 & 0.42 & 2.63 & 4.59 & 10.65 & 70.33 \\
\hline Finland & 5.10 & 2.29 & 3.81 & 1.65 & 0.35 & 0.73 & 135.59 & 10.35 & 135.71 \\
\hline France & 59.59 & 46.86 & 37.55 & 23.46 & 6.74 & 15.25 & 48.60 & 32.25 & 76.58 \\
\hline Germany & 258.45 & 143.40 & -48.74 & 28.06 & 25.23 & 10.02 & 40.42 & 67.60 & 28.68 \\
\hline Greece & 6.51 & 5.47 & 0.00 & 4.88 & 2.59 & 0.00 & 62.60 & 46.44 & 118.33 \\
\hline Hungary & 9.82 & 7.48 & -0.46 & 3.62 & 1.84 & 0.27 & 33.29 & 17.64 & 24.16 \\
\hline Ireland & 0.04 & 5.31 & 1.28 & 0.06 & 1.22 & 0.33 & 51.96 & 38.97 & 4.61 \\
\hline Italy & 152.27 & 22.81 & 13.56 & 87.58 & 2.71 & 5.95 & 95.88 & 5.68 & 7.86 \\
\hline Latvia & -0.12 & 0.09 & 0.19 & 0.11 & 0.04 & 0.10 & 24.29 & 53.64 & 19.26 \\
\hline Lithuania & 0.66 & -0.08 & -0.91 & 0.13 & 0.16 & 0.59 & 3.52 & 13.82 & 56.40 \\
\hline Norway & 1.94 & 0.07 & 5.48 & 0.53 & 0.05 & 1.84 & 54.17 & 7.88 & 24.79 \\
\hline Poland & 6.99 & 39.56 & -77.52 & 1.64 & 6.38 & 3.71 & 8.55 & 31.71 & 41.10 \\
\hline Portugal & 7.64 & 12.83 & -7.18 & 6.36 & 3.04 & 0.11 & 126.74 & 37.54 & 72.56 \\
\hline Romania & -31.15 & 2.62 & -3.56 & 0.63 & 0.72 & 0.12 & 8.28 & 9.81 & 6.08 \\
\hline Slovakia & -2.36 & 4.53 & 2.85 & 2.05 & 0.70 & 0.67 & 73.25 & 65.40 & 63.30 \\
\hline Slovenia & 5.70 & 4.07 & 1.60 & 1.16 & 0.78 & 0.33 & 19.17 & 101.90 & 114.56 \\
\hline Spain & 120.28 & 69.21 & 30.13 & 33.28 & 11.81 & 11.64 & 34.12 & 32.53 & 8.28 \\
\hline Sweden & 32.00 & 2.39 & 24.12 & 11.30 & 0.42 & 7.30 & 119.10 & 6.95 & 45.66 \\
\hline UK & 78.15 & -2.47 & 323.03 & 13.94 & 1.65 & 62.08 & 18.36 & 3.59 & 111.98 \\
\hline
\end{tabular}


ONLINE APPENDIX to the paper

The Impact of the Entry of Biosimilars: Evidence from Europe

Fiona M. Scott Morton, Ariel Dora Stern, and Scott Stern 


\section{Appendix A: Biosimilars in Australia and the United States}

\section{Australia}

Australia also has a regulatory pathway for biosimilar entry, and data from Australia are included in many of the analyses in this paper. Australian biosimilars are regulated by the Department of Health's Therapeutic Goods Administration (TGA), which borrows much of its regulatory policy from EU guidelines.

As with the EMA, the TGA defines a biosimilar or similar biological medicinal product (SBMP ${ }^{1}$ ) as a version of an already registered biological medicine that a) has a demonstrable similarity in physicochemical, biological and immunological characteristics, efficacy and safety, based on comprehensive comparability studies and b) has been evaluated by the TGA according to this guideline and other relevant EU guidelines adopted by the TGA. ${ }^{2}$

The Australian data requirements for the approval of biosimilars are based almost entirely on those outlined in EMA guidelines as well as an International Conference on Harmonisation of Technical Requirements for Registration of Pharmaceuticals for Human Use (ICH) guideline on the assessment of comparability. Additionally, the TGA requires the submission of a limited number of Australia-specific administrative documents. ${ }^{3}$ A full list of EU guidelines that have been adopted by the TGA for the approval of biosimilars can be found below, ${ }^{4}$ but for all intents and purposes, policies and standards that govern the

\footnotetext{
${ }^{1}$ Although referred to as biosimilars in Australia, the term `similar biological medicinal products' (SBMPs) is derived from the EU guidelines adopted by the TGA. The terms may be used interchangeably. In other jurisdictions, they also are variously referred to as: similar biotherapeutic products (WHO), follow-on biologics, and subsequent entry biologics.

${ }^{2}$ http://www.tga.gov.au/industry/pm-argpm-biosimilars-00.htm

${ }^{3}$ These include a Pre-Submission Planning Form (PPF), information for sponsors completing the PPF, mandatory requirements for an effective application, general submission dossier requirements, and a risk management plan guideline.

${ }^{4}$ Additional cites: adopted docs: CHMP/437/04: Guideline on similar biological medicinal products; EMEA/CHMP/BWP/49348/2005: Guideline on similar biological medicinal products containing Biotechnology-Derived Proteins as Active Substance: Quality Issues; CPMP/ICH/5721/03 ICH Topic Q 5 E: Comparability of Biotechnological/Biological Products Note for Guidance on Biotechnological/Biological Products Subject to Changes in their Manufacturing Process;

EMEA/CHMP/BMWP/42832/2005: Guideline on similar biological medicinal products Containing Biotechnology-Derived Proteins as Active Substances: Non-Clinical and Clinical Issues; CHMP/BMWP/101695/2006: Guideline on Comparability of BiotechnologyDerived Medicinal Products after a change in the Manufacturing Process - Non-Clinical and Clinical Issues; EMEA/CHMP/BMWP/14327/2006: Guideline on Immunogenicity Assessment of Biotechnology-Derived Therapeutic Proteins; Product-specific guidelines detailing the clinical and safety data requirements. (http://www.tga.gov.au/industry/pm-euguidelinesadopted-clinical.htm)
} 
approval of biosimilars in Australia are the same as those employed in the European Union and EMA decisions are adopted directly. Hence we include Australia in our empirical work. ${ }^{5}$

\section{THE United STATES}

At present, most biologic therapies available in the United States are regulated through the Public Health Service Act, which does not have a provision for "follow-on" versions of biologics (biosimilars). That is, there is no analog to generic chemical drugs as provided for under the Hatch-Waxman Act, which grants a 5 - 7.5 year data exclusivity period for NCEs. With the exception of some early biologics such as human growth hormone (hGH), insulin, and conjugated estrogens, which were approved as original drugs under the federal Food, Drug, and Cosmetic Act (FD\&C Act), biologics in the United States are regulated separately from chemical drugs by the FDA. ${ }^{6}$ Biologics are regulated by the Center for Biologics Evaluation and Research (CBER), while small molecule drugs are regulated by the Center for Drug Evaluation and Research (CDER). In April of 2015, the FDA released final regulatory guidance on several, but not all aspects of the biosimilar approval process. The three final guidance documents issued address 1) "Scientific Considerations in Demonstrating Biosimilarity to a Reference Product”; 2) “Quality Considerations in Demonstrating Biosimilarity of a Therapeutic Protein Product to a Reference Product”; and 3) “Questions and Answers Regarding Implementation of the Biologics Price Competition and Innovation Act of 2009.”7, 8, 9 The first of these documents, which is the most important of the three "is intended to assist sponsors in demonstrating that a proposed therapeutic protein product... is biosimilar to a reference product for purposes of the submission of a marketing application” (FDA, 2015). Importantly, the FDA has not yet released regulatory guidance to clarify the type and level of evidence required for interchangeability of biosimilars and reference biologics, which the FDA will release in a future guidance document. The FDA approved the first biosimilar application in March

\footnotetext{
${ }^{5}$ However all empirical results presented below are robust to excluding Australia from the sample.

${ }^{6}$ Biologics have 12 years of data exclusivity in the US, compared to 5 for small molecules.

${ }^{7} \mathrm{http}: / /$ www.fda.gov/downloads/Drugs/GuidanceComplianceRegulatoryInformation/Guidances/UCM291128.pdf

${ }^{8} \mathrm{http} / / /$ www.fda.gov/downloads/Drugs/GuidanceComplianceRegulatoryInformation/Guidances/UCM291134.pdf

${ }^{9} \mathrm{http}: / /$ www.fda.gov/downloads/Drugs/GuidanceComplianceRegulatoryInformation/Guidances/UCM444661.pdf
} 
2015, Sandoz's Zarxio (Filgrastim), ${ }^{10}$ and three subsequent biosimilars (not yet launched at the time of writing) in 2016. Zarxio was marketed beginning in March 2015 at a launch price 15\% below the reference biologic Neupogen.

On February 4 of 2016, the Director of the Center for Drug Evaluation and Research (CDER) testified that " 59 proposed biosimilar products to 18 different reference products were enrolled in the Biosimilar Product Development Program."11 Enrolling in this program appears to both indicate interest in launching a product and also allows the applicant to meet with CDER, which Dr. Woodcock testified was happening with great frequency. She also said that as of December $31^{\text {st }} 2015$ five companies had publicly announced eight biosimilar applications. At the time of writing, only four biosimilar products ${ }^{12}$ had been approved by the FDA and only one of those, Sandoz's Zarxio, had been launched.

\footnotetext{
${ }^{10} \mathrm{http} / /$ www.fda.gov/NewsEvents/Newsroom/PressAnnouncements/ucm436648.htm

${ }^{11}$ Testimony by Dr. Woodcock before the House Committee on Energy and Commerce, subcommittee on Health, February 4, 2016.

12 The four FDA-approved biosimilars as of January, 2017 were: 1) Zarxio, biosimilar to Neupogen, approved in March, 2015; 2) Inectra, biosimilar to Remicade, approved in April, 2016; 3) Erlezi, biosimilar to Enbrel, approved in August, 2016; and 4) Amjevita biosimilar to Humira, approved in September, 2016.
} 
Appendix B: Supplementary Figures 
Figure I. Biosimilar share of total domestic Epoetin/Filgrastim \& Somatropin market (standard units) by country, 2007-2014

* Fraction of total standard units that are biosimilar, conditional on biosimilar units $>.001$ of total units

Biosimilar share of Epoetin market, by units sold

1.2

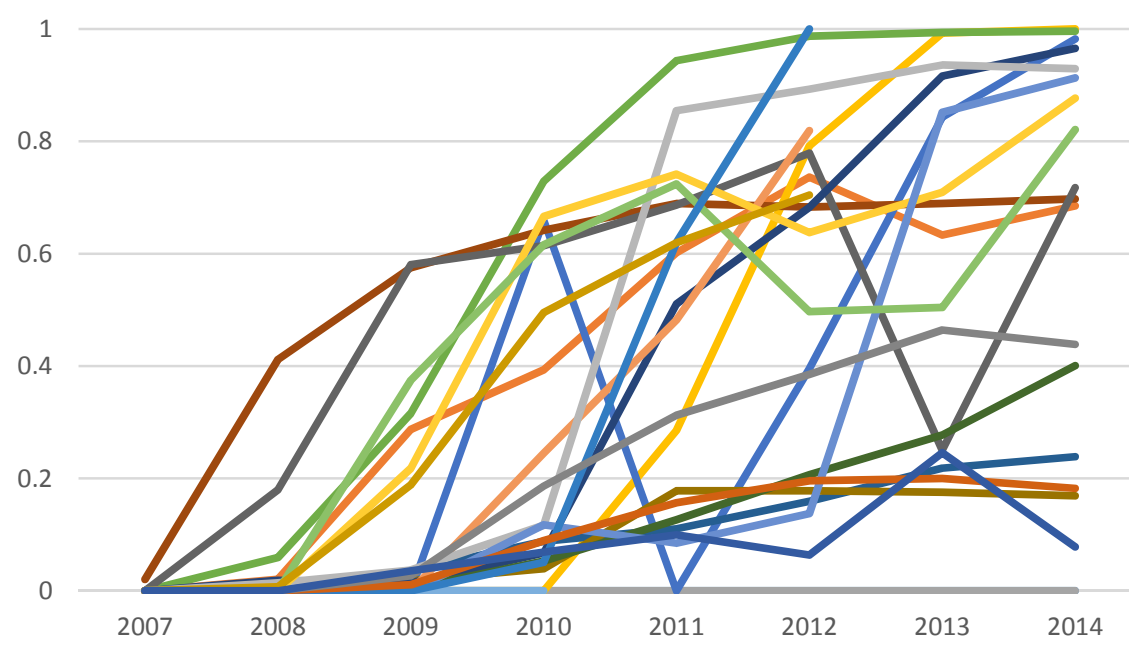

Biosimilar share of Filgrastim market, by units sold

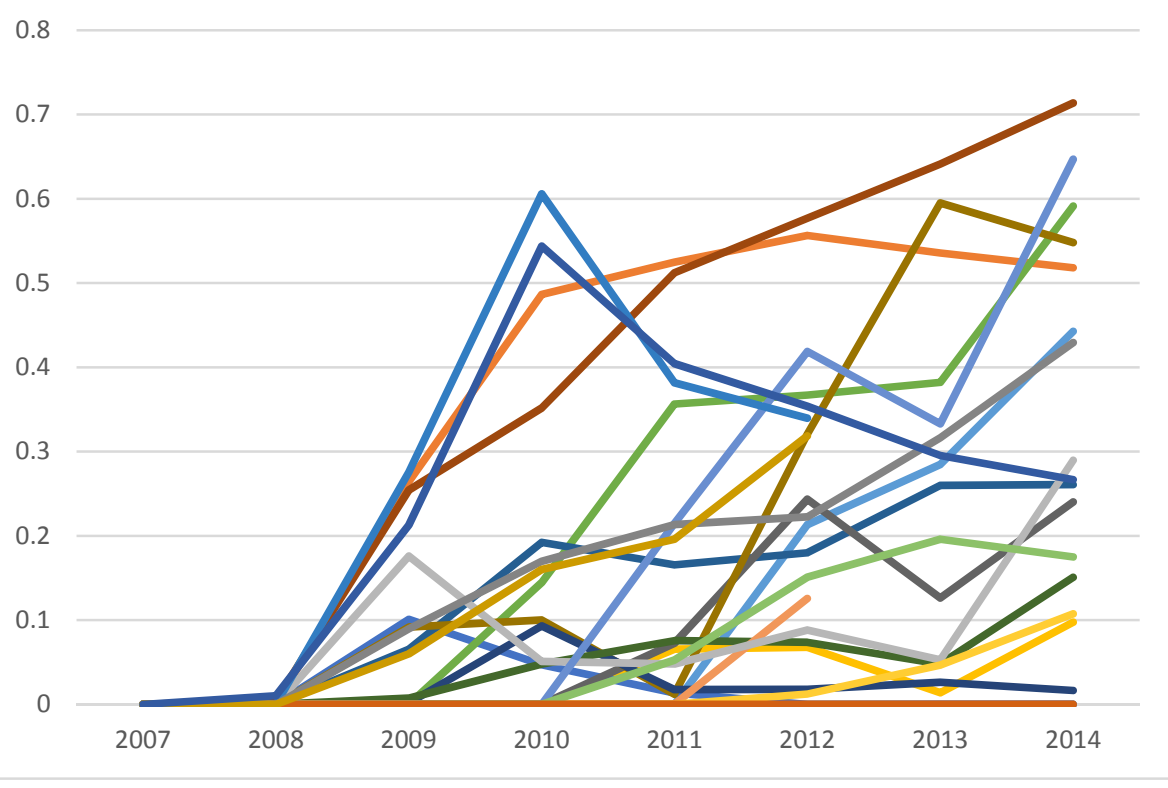

Biosimilar share of Somatropin market, by units sold
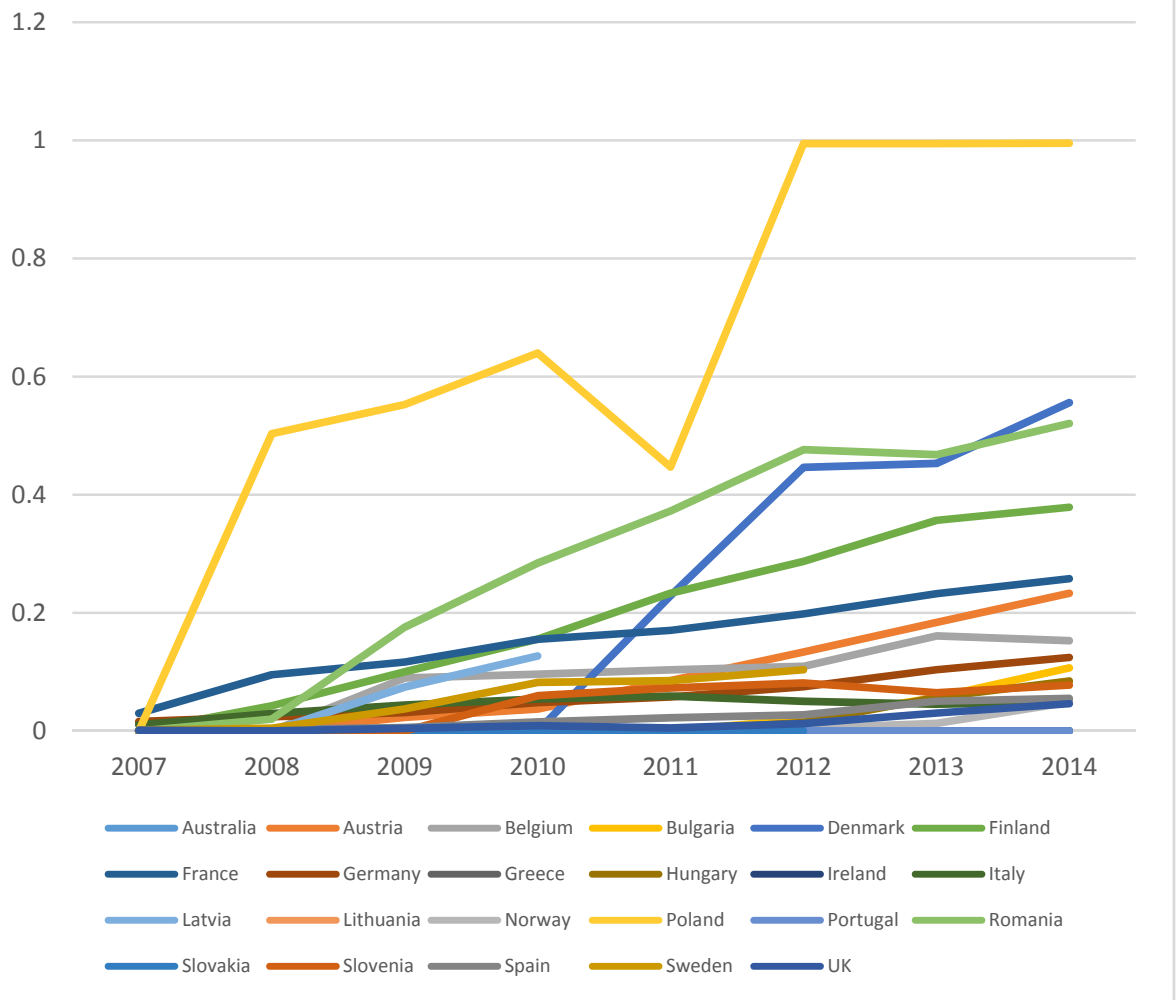
Figure II. Total sales in domestic Epoetin/Filgrastim/Somatropin markets (1000s units), 2007-2014

* Total biosimilar sales, conditional on biosimilar units $>.001$ of total units

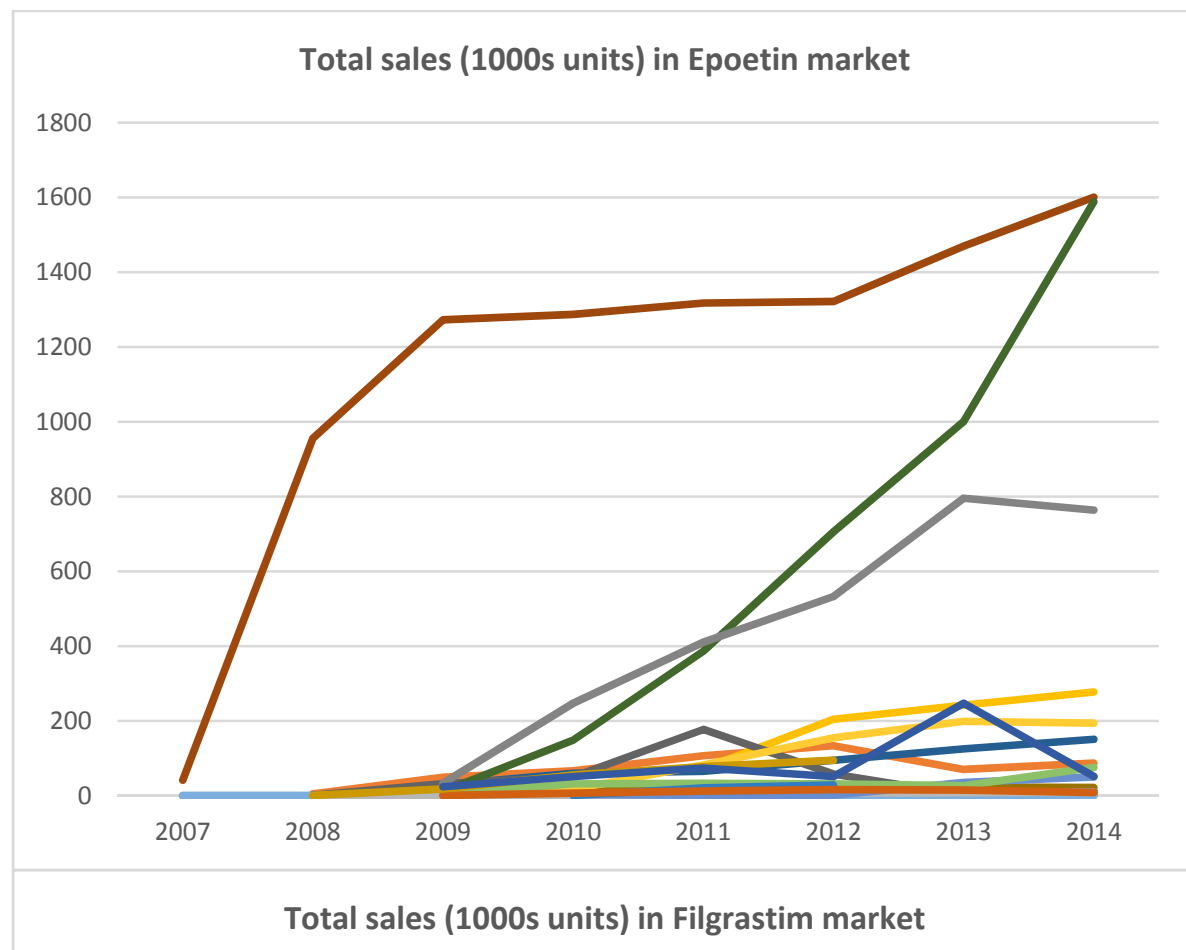

600
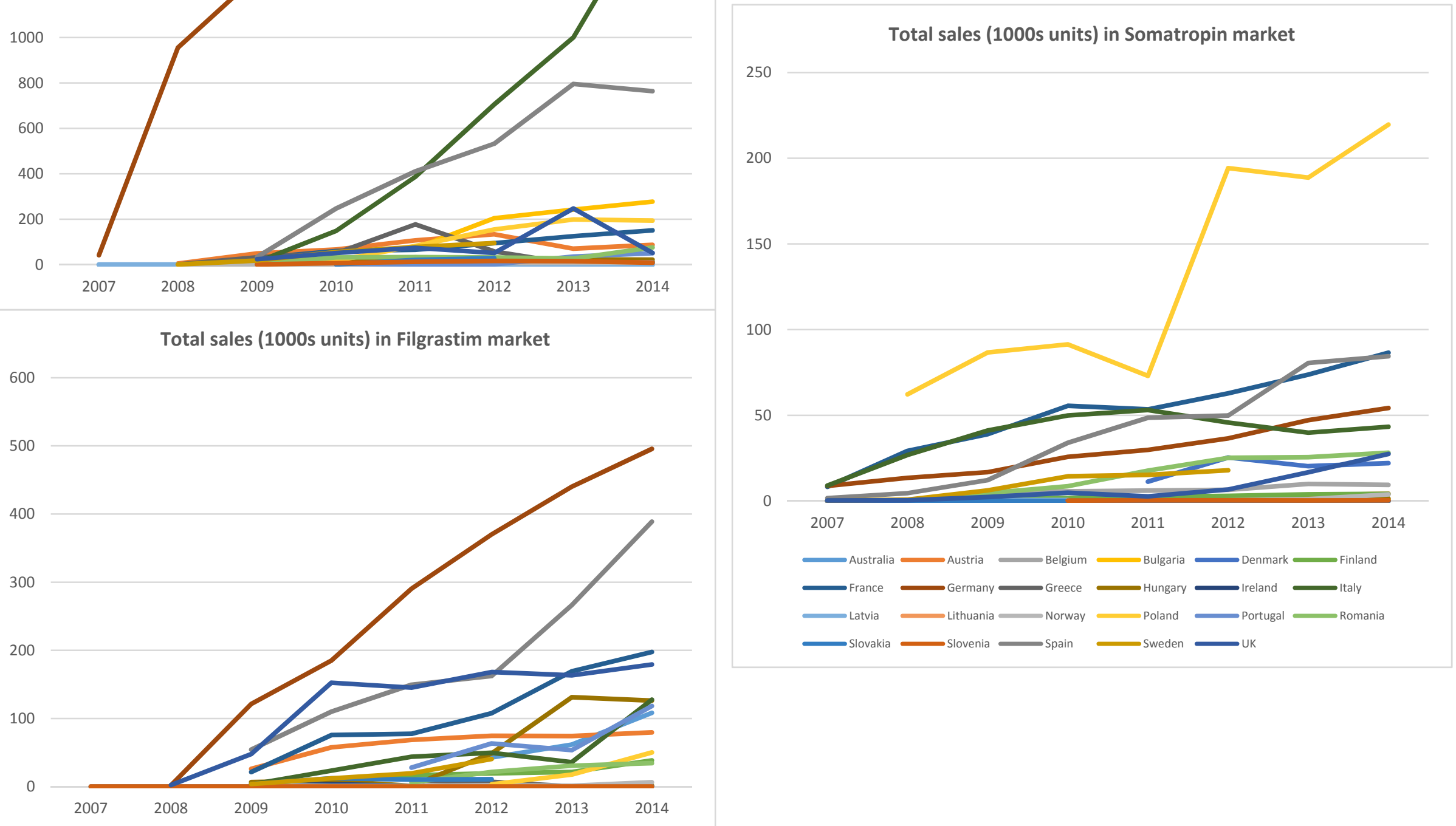
Figure III. Total sales in domestic Epoetin/Filgrastim/Somatropin markets (1000s 2006 dollars), 2007-2014

* Total biosimilar sales, conditional on biosimilar units $>.001$ of total units
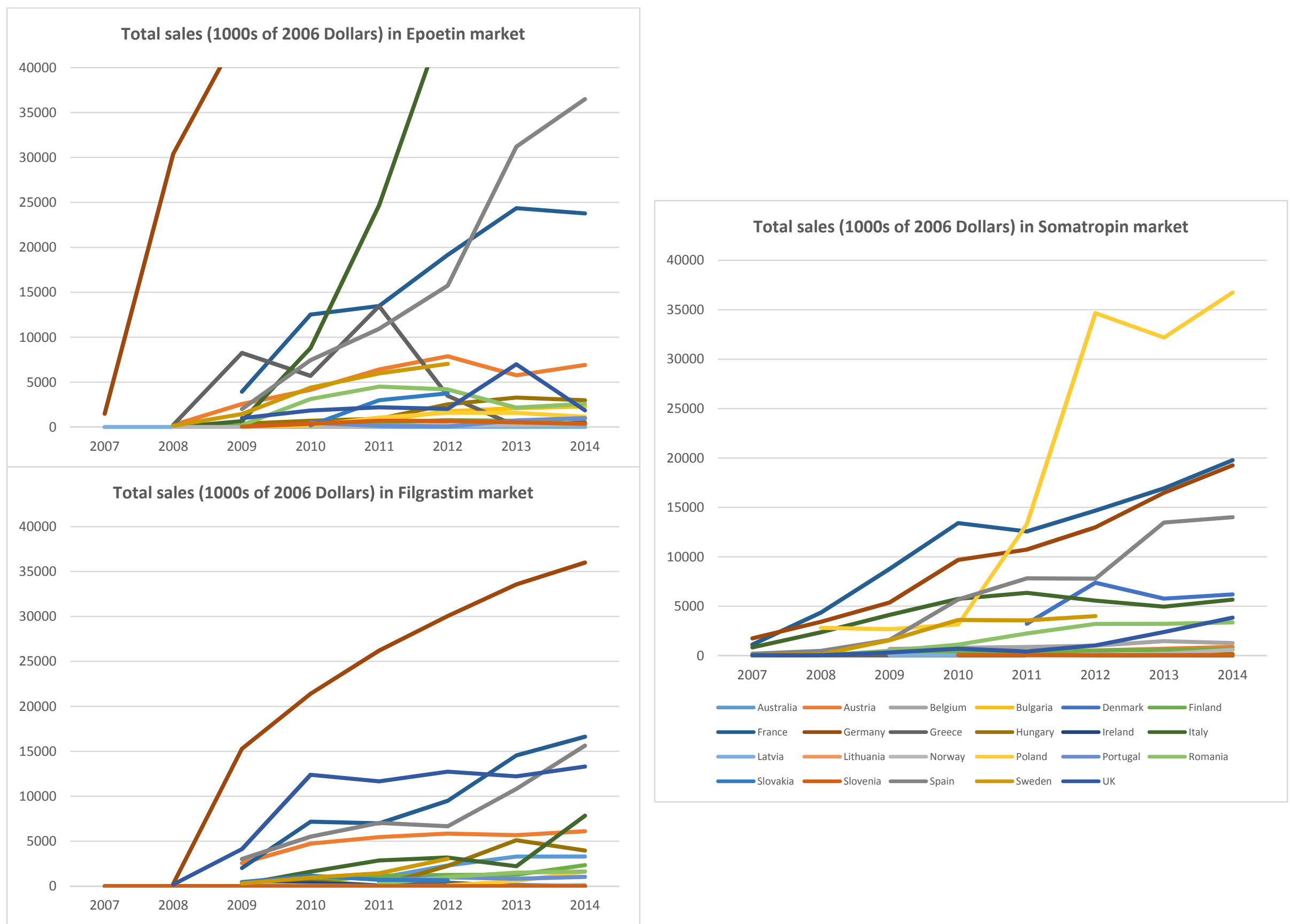
Figure IV. Relative prices: biosimilar vs. base year reference product price, Epoetin/Filgrastim/Somatropin, 2007-2014

* Relative prices, conditional on biosimilar units $>.001$ of total units

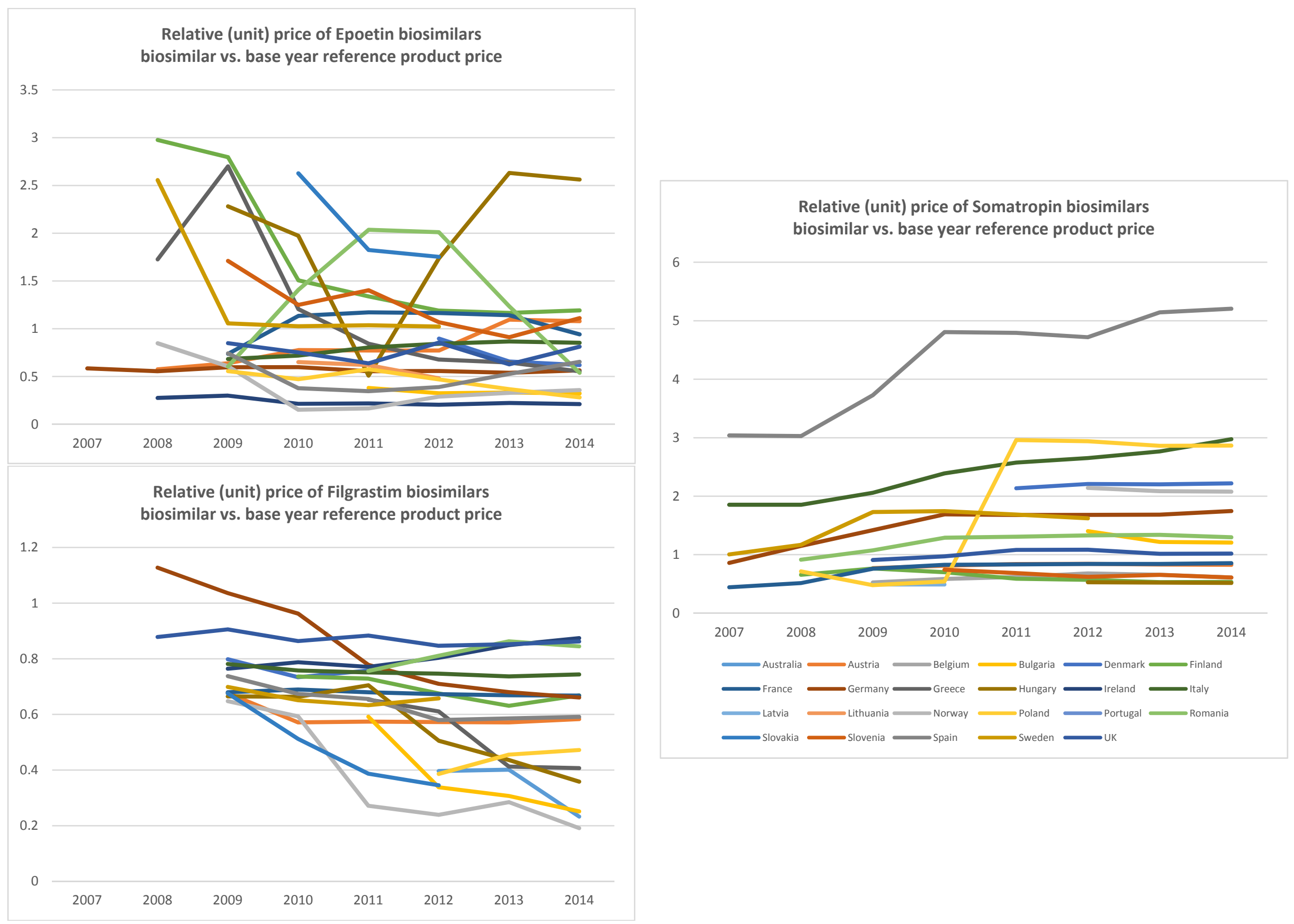


Figure V. Relative prices: average market price in current year vs. base year ref product price, Epoetin/Filgrastim/Somatropin, 2007-2014

* Relative prices, conditional on biosimilar units $>.001$ of total units

Relative (unit) price of Epoetin biosimilars

avg current mkt price vs. base year ref product price

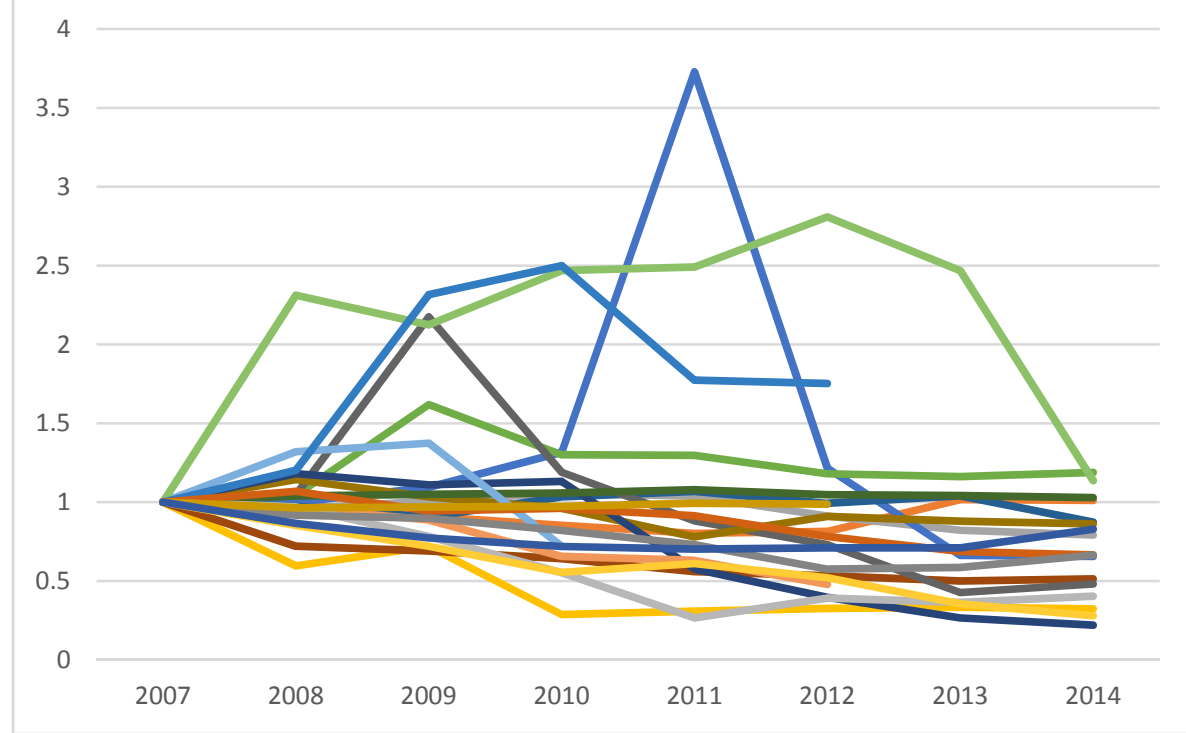

Relative (unit) price of Filgrastim biosimilars avg current mkt price vs. base year ref product price

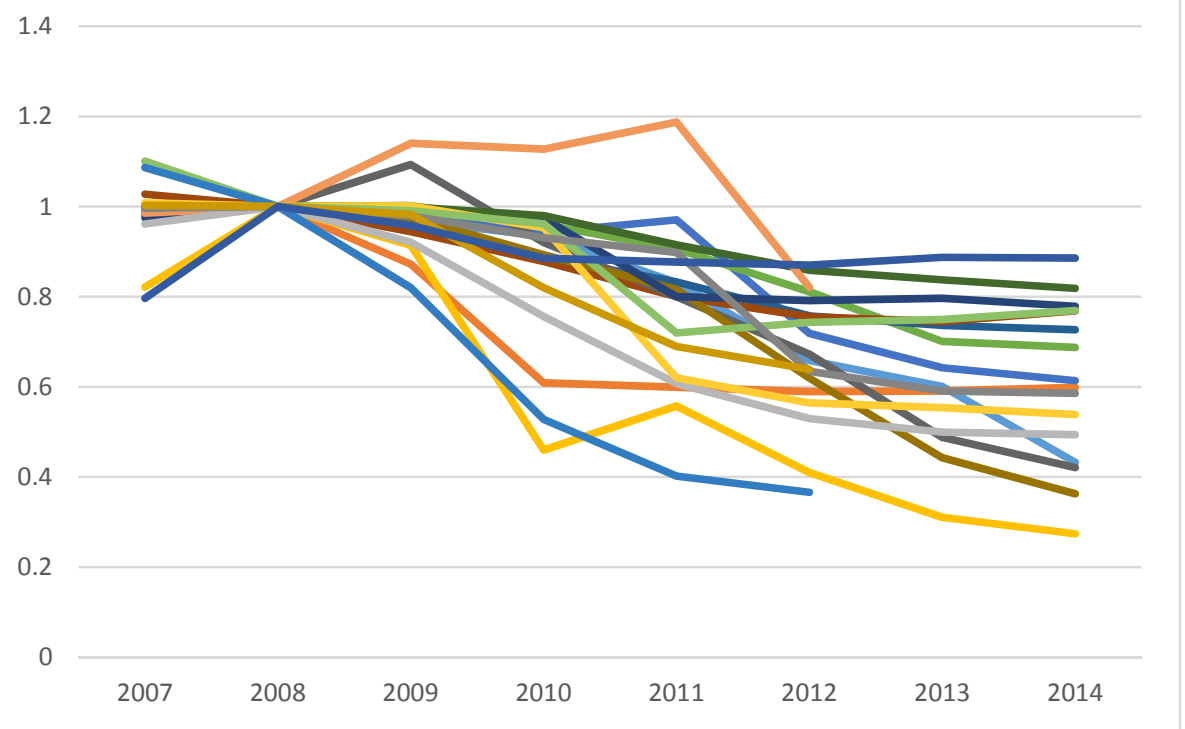

Relative (unit) price of Somatropin biosimilars avg current mkt price vs. base year ref product price 3.5

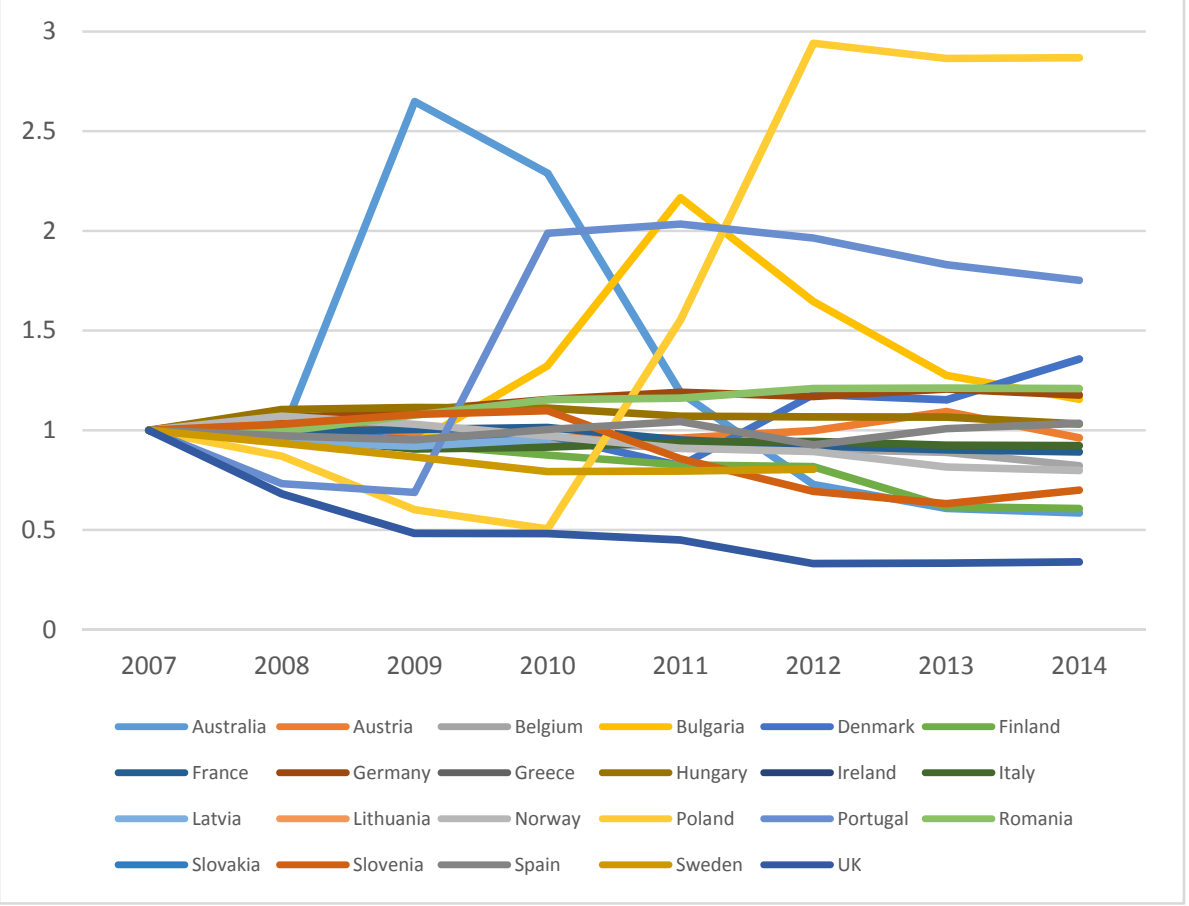


Appendix C: Supplementary Tables 
Table I. Legal requirements for a new biosimilar application to the EMA

The legal requirements of a new biosimilar application include all of the following:

- Administrative data

- Summary of product characteristics

- Expert reports

- Qualitative and quantitative particulars of the constituents. ${ }^{13}$

- Description of manufacturing method

- Controls of starting materials

- Specific measures concerning the prevention of the transmission of animal spongiform encephalopathies

- Control tests carried out at intermediate stages of the manufacturing process

- Control tests on the finished product (including general characteristics of the finished product, identification and assay of active substance(s), identification and assay of excipient constituents, safety tests)

- Stability and toxicity tests

- Examination of reproductive function and embryo/foetal and perinatal toxicity tests

- Tests of mutagenic potential, carcinogenic potential

- Data on pharmacodynamics and pharmacokinetics

- Local tolerance tests

- Well-established medicinal use

- Conduct of trials

- Presentation of results

- Clinical pharmacology

- Bioavailability/bioequivalence

- Clinical efficacy and safety

- Documentation for applications in exceptional circumstances

- Post-marketing experience

- Well-established medicinal use

\footnotetext{
${ }^{13}$ Active substances present in the form of compounds or derivatives shall be designated quantitatively by their total mass, and if necessary or relevant, by the mass of the active entity or entities of the molecule. For allergen products, the quantitative particulars shall be expressed by units of biological activity, except for well-defined allergen products for which the concentration may be expressed by mass/unit of volume.
} 
Table II. List of sample countries with first year of biosimilar entry* in each market, 2007-2014

Epoetin Filgrastim Somatropin

\begin{tabular}{llll}
\hline First EMA Approval & 2007 & 2008 & 2006 \\
\hline Australia & & 2012 & 2007 \\
Austria & 2008 & 2009 & 2009 \\
Belgium & & & 2009 \\
Bulgaria & 2011 & 2011 & 2012 \\
Denmark & 2010 & 2009 & 2011 \\
Finland & 2008 & 2010 & 2008 \\
France & 2009 & 2009 & 2007 \\
Germany & 2007 & 2008 & 2007 \\
Greece & 2008 & 2011 & \\
Hungary & 2009 & 2009 & 2012 \\
Ireland & 2008 & 2009 & \\
Italy & 2009 & 2009 & 2007 \\
Latvia & & & 2009 \\
Lithuania & 2010 & 2012 & \\
Norway & 2008 & 2009 & 2012 \\
Poland & 2009 & 2012 & 2008 \\
Portugal & 2010 & 2011 & \\
Romania & 2009 & 2011 & 2008 \\
Slovakia & 2010 & 2009 & \\
Slovenia & 2009 & & 2010 \\
Spain & 2009 & 2009 & 2007 \\
Sweden & 2008 & 2009 & 2007 \\
UK & 2009 & 2008 & 2007 \\
\hline Conditina & & \\
\end{tabular}

*conditional on biosimilar units $>.001$ of total domestic units sold 


\section{Table III. List of individuals/organizations that assisted with policy survey}

Andreja Jerina, The Directorate for Health, Sector for the development of health care, Slovenian Health Ministry, Slovenia

Carlos Lens, Pharmacy Deputy Director in the Ministry of Health, Social Services and Equality (MSSSI), Spain Claire Biot, Director at Agence Générale des Equipements et Produits de Santé (AGEPS) AP-HP, France

Dr Maria Skouroliakou, Assistant Professor of Enteral and Parenteral Nutrition, School of Health Science \& Education, Greece

Dr. Helder Mota Filipe, Associate Professor of Pharmacology and Therapeutics and Vice-President of Executive Board, INFARMED (National Authority of Medicines and Health Products, IP Portugal), Portugal

Dr. Fernando de Mora, Universitat Autònoma de Barcelona, Spain

Gustaf Befrits, Administrator in Pharma department of Stockholm County Council, Sweden

Hannes Enlund, FIMEA (Finnish Medicines Agency), Finland

Helga Festoy, Norwegian Medicines Agency, Norway

Italian Medicines Agency, Italy

Jens Ersboll, Danish Medicines Agency, Denmark

Karen Binnekamp, Pricing area of Department of Health, administer pharmaceutical benefit scheme (PBS), Australia

Maria Isabel Farfan, Expert economist, Belgium

Matthias Diesel, Head of Market Access, Pro Generika, Germany

Ministry of Health, Poland

Monika Lainczova, Manager of Drug Policy Deparment, Dovera Health Insurance Company, Slovakia

National Agency, Denmark

Pablo Serrano, Federal Association of the Pharmaceutical Industry BPI (Bundesverband der Pharmazeutischen Industrie e.V.), Germany

Roger Purcell, National Health Service, UK

Sabine Vogler, Gesundheit Österreich GmbH, Austria

Sandoz, Slovenia

Stanislav Primozic, Deputy Director of JAZMP, Slovenia

VFA Bio, Germany 